\title{
The Lower-Stratospheric Response to 11-Yr Solar Forcing: Coupling to the Troposphere-Ocean Response
}

\author{
LON L. HOOD AND BORIS E. SOUKHAREV \\ Lunar and Planetary Laboratory, The University of Arizona, Tucson, Arizona
}

(Manuscript received 17 March 2011, in final form 16 February 2012)

\begin{abstract}
The origin of the tropical lower-stratospheric response to 11-yr solar forcing and its possible coupling to a troposphere-ocean response is investigated using multiple linear regression (MLR) analyses of stratospheric ozone and temperature data over the 1979-2009 period and tropospheric sea level pressure (SLP) data over the 1880-2009 period. Stratospheric MLR results, comparisons with simulations from a chemistryclimate model, and analyses of decadal variations of meridional eddy heat flux indicate that the tropical lowerstratospheric response is produced mainly by a solar-induced modulation of the Brewer-Dobson circulation (BDC), with a secondary contribution from the Hadley circulation in the lowermost stratosphere. MLR analyses of long-term SLP data confirm previous results indicating a distinct positive response, on average, during the northern winter season in the North Pacific. The mean response in the Northern Hemisphere resembles a positive Arctic Oscillation mode and can also be characterized as "La Niña-like," implying a reduction of Rossby wave forcing, a weakening of the BDC, and an increase in tropical lower-stratospheric ozone and temperature near solar maxima. However, MLR analyses of different time periods show that the Pacific SLP response is not always present during every cycle; it was most clearly detected mainly during the 1938-93 period when 11-yr solar variability was especially strong. During the 1979-93 period, the SLP response was strongly present when the lower-stratospheric responses were large. But during the 1994-2009 period, the SLP response was much less significant and the lower-stratospheric responses were weak, supporting the hypothesis that the lower-stratospheric and surface climate responses are dynamically coupled.
\end{abstract}

\section{Introduction}

Observational studies of stratospheric ozone and temperature records obtained since the onset of continuous global satellite measurements in late 1978 indicate the existence of statistically significant responses to 11-yr solar forcing at tropical and subtropical latitudes (for reviews, see Hood 2004, WMO 2007, and Gray et al. 2010). In addition to an upper-stratospheric response that is attributable to direct photochemical and radiative forcing, a significant 11-yr variation has also been observed in the lower stratosphere that appears to be dynamical in origin and is much less well understood.

Several possible mechanisms for explaining the observed lower-stratospheric response have been suggested. First, it is possible that direct UV-induced photochemical and thermal forcing of the upper stratosphere can modify

Corresponding author address: Lon L. Hood, Lunar and Planetary Laboratory, The University of Arizona, 1629 E. University Blvd., Tucson, AZ 85721.

E-mail: lon@lpl.arizona.edu ozone concentrations, zonal winds, planetary wave propagation, and absorption causing a deceleration of the mean meridional Brewer-Dobson circulation (BDC) near solar maxima (Kodera and Kuroda 2002; Nathan and Cordero 2007; Powell and Xu 2011). The reduced upwelling rates would advectively increase ozone mixing ratios in the tropical lower stratosphere, leading to associated radiative temperature increases. Possible secondary effects on tropospheric circulation include a weakening and poleward shift of the subtropical jets and a broadening of the Hadley cells (Haigh 1996; Haigh et al. 2005; Rind et al. 2008; Simpson et al. 2009). In support of this "topdown" mechanism, Gray et al. (2001a,b; see also Cnossen et al. 2011) showed that winds in the tropical upper stratosphere and lower mesosphere play a significant role in imposing a solar influence on the winter polar vortex state, as identified in observations originally by Labitzke and van Loon (1988). More recently, Matthes et al. $(2004,2006,2010)$ have shown that combined influences of the equatorial quasi-biennial wind oscillation (QBO) and the solar cycle on the polar stratosphere and an associated weakening of the tropical upwelling rate 
can be partly simulated in a general circulation model that includes a relaxation toward observed equatorial winds in the upper stratosphere, consistent with the results of Gray et al. (2001a,b). However, most free-running chemistry-climate models (CCMs), including those with a coupled troposphere and ocean, have not yet simulated the full magnitude and persistence during all seasons of the observed tropical lower-stratospheric response.

Second, it is possible that a measurable response of the troposphere-ocean system to the 11-yr solar cycle exists, resulting from either (a) total solar irradiance (TSI) variations or (b) indirect dynamical effects of solar forcing of the stratosphere, or both. If so, then this troposphere-ocean response may have significant positive feedback effects on tropical circulation, which would in turn have consequences for ozone and temperature in the tropical and subtropical stratosphere. There is some observational evidence for an 11-yr variation of global sea and land surface temperatures with a mean amplitude of approximately $0.1 \mathrm{~K}$ (White et al. 1997; Tung and Camp 2008; Zhou and Tung 2010), for 11-yr sea surface temperature (SST) and sea level pressure (SLP) anomalies in the Pacific region (Christoforou and Hameed 1997; van Loon et al. 2007; Roy and Haigh 2010; Tung and Zhou 2010), and for a solar cycle variation of temperatures in the equatorial middle troposphere (Salby and Callaghan 2006). Model studies suggest that an amplification of initially weak solar forcing of the ocean-troposphere system can occur through positive evaporation and cloud feedbacks (Meehl et al. 2003, 2008, 2009; Bal et al. 2011). It is well known that El NiñoSouthern Oscillation (ENSO) events can modify wave forcing and propagation with effects on the winter polar vortex state and the BDC, and hence on ozone and temperature in the tropical lower stratosphere (GarcíaHerrera et al. 2006; Free and Seidel 2009; Randel et al. 2009b; Calvo et al. 2010; Hood et al. 2010; Garfinkel and Hartmann 2008). It is therefore possible that any significant response of the troposphere-ocean system to solar forcing will have feedback effects on the stratospheric response. In support of this "bottom-up" mechanism, many CCMs that are forced at their lower boundaries using observed SSTs are able to produce a lower-stratospheric response that is qualitatively similar to that which is observed (Austin et al. 2007, 2008; Garcia et al. 2007; Matthes et al. 2007). Also, a recent study by Cnossen and Lu (2011) finds that solar-related geopotential height anomalies in the troposphere over the Aleutian low during $\mathrm{NH}$ early winter are vertically connected to anomalies in the stratosphere under QBOwest conditions.

Third, it is possible that ozone variations forced by the QBO contribute to the observed lower-stratospheric solar cycle response. There is some evidence for an increased length of the QBO-west phase during solar minimum conditions (Salby and Callaghan 2000; Soukharev and Hood 2001), although the short measurement record makes it difficult to evaluate statistical significance (Hamilton 2002; Fischer and Tung 2008). A solar-induced modulation of the QBO-west-phase length could result from direct solar UV heating changes in the upper stratosphere (McCormack 2003; McCormack et al. 2007), wave-ozone feedbacks (Cordero and Nathan 2005), and/ or from solar-induced changes in tropical upwelling rates, which would modify the descent rate of QBO easterlies (Pascoe et al. 2005; Kinnersley and Pawson 1996). In support of this possibility, a small secondary ozone response maximum in the tropical lower stratosphere was produced in the experiments of McCormack et al. (2007; see their Fig. 18). However, the overall vertical response profile still differed substantially from the observed response profile and the model response was limited to low latitudes $\left(\leq 20^{\circ}\right)$.

Finally, several authors have suggested that the lowerstratospheric response maximum may be partly or entirely an artifact resulting from aliasing of the solar cycle response by the QBO, volcanic aerosol injections, and/ or ENSO events (Lee and Smith 2003; Smith and Matthes 2008; Marsh and Garcia 2007). This possibility must always be seriously considered since the statistical technique that is usually employed is multiple linear regression (MLR), which makes the simplified assumption that all forcings are orthogonal (i.e., independent of one another) and that all responses are linear. Difficulties in completely separating the QBO ozone signal from the solar cycle ozone signal have been demonstrated, for example, by Smith and Matthes (2008) using an interactive 2D model. However, their simulated ozone response profiles did not include a significant lowerstratospheric ozone response maximum. In contrast, at least some of the 3D CCM simulations forced with observed SSTs used by Austin et al. (2008) did not have a prescribed or internally forced QBO but were nevertheless able to simulate a lower-stratospheric response. Therefore, although further work to investigate interference from the QBO using 3D models is worthwhile, it remains unclear whether this is the explanation for the observed response. It is also possible, in principle, that an accidental correlation of ENSO events with the solar cycle during a limited time period could lead to a bias in the statistically estimated solar regression coefficients (Marsh and Garcia 2007). However, tests involving analysis of satellite ozone datasets using a regression model with and without an ENSO term have not indicated a significant bias for the 1979-2003 time period (Hood et al. 2010). 
In this paper, we investigate further the origin of the observed tropical and subtropical lower-stratospheric response to 11-yr solar forcing, especially whether positive dynamical feedbacks from a coupled troposphereocean response may be playing a significant role. In section 2, the latitude, altitude, and seasonal dependences of the 11-yr lower-stratospheric ozone and temperature responses are further determined through updated MLR analyses of available long-term records. Comparisons are also made with MLR analyses of model data from a simulation using a chemistry-climate model with a prescribed QBO and a coupled troposphere and ocean. The results are interpreted as indicating an apparent 11-yr solar modulation of the BDC that is not fully simulated in the model. In section 3, evidence for decadal variability of the BDC is evaluated using meridional eddy heat fluxes calculated from National Centers for Environmental Predication (NCEP)-National Center for Atmospheric Research (NCAR) reanalysis data. A simplified analytic model is then applied to test whether such variability could have contributed to producing the observed solar cycle variation of the tropical lower stratosphere. In section 4 , the troposphere-ocean response to 11-yr solar forcing is characterized further by carrying out MLR analyses of Hadley Centre SLP data during NH winter over the $\sim 1880-2009$ period. For comparison, corresponding ENSO regression coefficients are also calculated for zonal mean ozone, temperature, and SLP, expressed as the response to a -1 unit change in the Niño-3.4 index. In section 5, the reality of the SLP solar response and the hypothesis of dynamical coupling to the tropical lower-stratospheric response are tested further by carrying out MLR analyses of SLP, column ozone, and 50-hPa temperature during separate periods when 11-yr solar variations and the resulting SLP response were strong and weak, respectively. Conclusions are given in section 6.

\section{Lower-stratospheric ozone and temperature responses}

Figure 1 compares deviations from long-term monthly means, averaged over low latitudes, of (a) the version 8 merged Total Ozone Mapping Spectrometer/Solar Backscattered Ultraviolet (TOMS/SBUV) total ozone record compiled at Goddard Space Flight Center (e.g., Frith and Stolarski 2005) and (b) NCEP-NCAR reanalysis 50-hPa temperature data (e.g., Kalnay et al. 1996) to (c) the daily solar Mg II UV index (Viereck and Puga 1999). At least three sources of decadal variability are evident in the column ozone and lower-stratospheric temperature records. First, there is a long-term, at least partly anthropogenic trend. This trend was roughly linear and

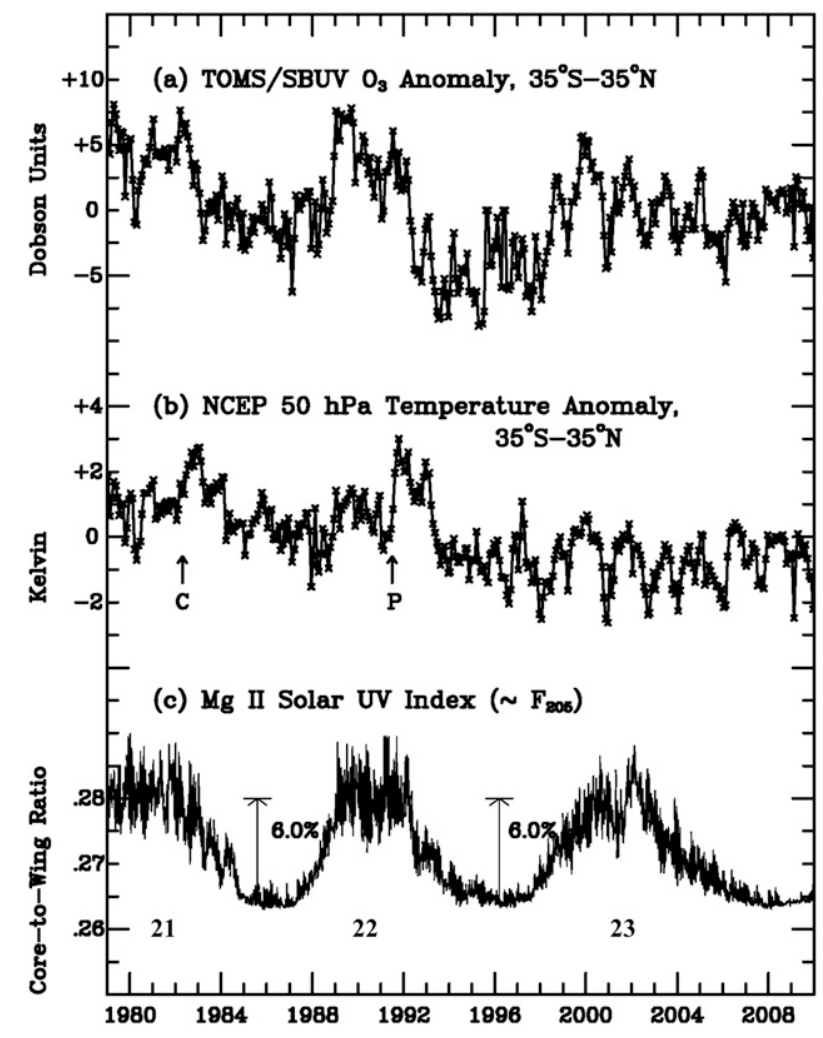

FIG. 1. (a) Area-weighted average over $35^{\circ} \mathrm{S}-35^{\circ} \mathrm{N}$ of the TOMS/ SBUV ozone deviation from the long-term monthly mean. (b) As in (a), but for 50-hPa temperature using NCEP-NCAR reanalysis data; the times of the El Chichón $(\mathrm{C})$ and Pinatubo $(\mathrm{P})$ volcanic eruptions are also indicated. (c) Monthly Mg II solar UV index. See the text for data sources.

negative until the middle to late 1990s but has since been noticeably reduced in amplitude (WMO 2007, ch. 3). Second, significant ozone decreases and temperature increases occur following the major volcanic eruptions of El Chichón in late March/early April 1982 and Pinatubo in June 1991 (Solomon et al. 1996; Robock 2000; Stenchikov et al. 2002). Third, there is a tendency for higher averages near maxima of the 11-yr solar cycle for both ozone (e.g., Hood and McCormack 1992; Hood 1997; Zerefos et al. 1997; Soukharev and Hood 2006; Randel and Wu 2007; Tourpali et al. 2007) and temperature (e.g., Steinbrecht et al. 2003; Labitzke 2004; Crooks and Gray 2005; Randel et al. 2009a; Gray et al. 2009). The volcanic and trend contributions are strongest at middle and high latitudes where heterogeneous chemical losses and dynamical transport are most important (e.g., Brasseur and Solomon 2005). However, at low latitudes, the solar contribution appears to dominate, as seen in the figure. The solarinduced variation of ozone was especially pronounced during cycles 21 and 22 but was somewhat diminished during the most recent cycle 23 . 
For several reasons, it is unlikely that the decadal variation of low-latitude column ozone shown in Fig. 1a could be a fortuitous consequence of the two major volcanic eruptions (El Chichòn and Pinatubo), which both occurred following solar maxima in this time period. First, the timing of the major decadal ozone increases and decreases corresponds more closely to increases and decreases of solar irradiance (e.g., UV flux as shown in Fig. 1c) than to the times of the two eruptions. The Pinatubo eruption occurred in June 1991 while the main column ozone decrease at latitudes of $35^{\circ}$ or less occurred about a year later at nearly the same time as a rapid decrease in solar irradiance in early to middle 1992. The rapid increase in ozone during 1988 corresponds closely with an increase in irradiance during the same year and the more gradual increase in ozone during 1997-99 corresponds well with a more gradual irradiance increase during the same years. Second, ground-based column ozone data at low latitudes can be used to extend the available record backward in time by one or two more solar cycles (WMO 2007, ch. 3). These data show that the solar cycle variation of column ozone at low latitudes continues at least back to the middle 1960 s, during a period when there were no major volcanic eruptions (see Fig. 3.4 of WMO 2007). Third, the volcanically induced lower-stratospheric temperature increases produced by the El Chichòn and Pinatubo eruptions are distinguishable in Fig. $1 \mathrm{~b}$ and are limited to several years after each eruption. Solar-related temperature increases occur in 1988 and 1998/99 in association with irradiance and column ozone increases. The column ozone increases at these times must therefore be mainly solar in origin.

Detailed MLR statistical analyses of available long-term ozone profile datasets to evaluate the vertical structure of the tropical ozone solar cycle response have previously been reported by a number of analysts (e.g., Soukharev and Hood 2006; Randel and Wu 2007; Tourpali et al. 2007; Remsberg 2008; Hood et al. 2010). MLR analyses to determine the vertical structure of the tropical temperature response have also been reported (Haigh 2003; Crooks and Gray 2005; Shibata and Deushi 2008; Randel et al. 2009a; Frame and Gray 2010). These analyses generally confirm that the tropical ozone and temperature responses are significantly positive in the upper stratosphere, statistically insignificant in the equatorial middle stratosphere $(\sim 10 \mathrm{hPa})$ and significantly positive again in the lower stratosphere [see, e.g., Figs. 10 and 11 of Gray et al. (2010)].

Here, we first present updated MLR results for the latitude, altitude, longitude, and seasonal dependences of stratospheric ozone and temperature solar regression coefficients using an extended data record and an improved
MLR statistical model. Then, the zonal mean ozone and temperature responses are compared to those derived from a simulation by a chemistry-climate model with a prescribed QBO and a coupled troposphere and ocean.

To represent the temporal behavior of a given atmospheric variable (e.g., column ozone) $X(t)$, we use an MLR model similar to that used previously (e.g., Hood et al. 2010) but with the addition of a change-of-trend term to account for a possible change in long-term trends during the data interval:

$$
\begin{aligned}
X(t)= & \mu(i)+\beta_{\text {trend }} t+\beta_{\mathrm{QBO} 1} u_{30 \mathrm{hPa}}(t)+\beta_{\mathrm{QBO} 2} u_{10 \mathrm{hPa}}(t) \\
& +\beta_{\text {volcanic }} \text { Aerosol }(t)+\beta_{\text {solar }} \operatorname{Solar}(t) \\
& +\beta_{\mathrm{ENSO}} \mathrm{N} 3.4\left(t-\operatorname{lag}_{\mathrm{ENSO}}\right)+\beta_{\Delta \text { trend }} t^{\prime}
\end{aligned}
$$

where $t$ is the time in some chosen increment (e.g., months); $\mu(i)$ is the long-term mean for the $i$ th month $(i=1,2, \ldots, 12)$ or season $(i=1,2, \ldots, 4)$ of the year; $u_{30 \mathrm{hPa}}$ and $u_{10 \mathrm{hPa}}$ are the 30 - and $10-\mathrm{hPa}$ equatorial zonal winds; Aerosol $(t)$ is a stratospheric volcanic aerosol index; $\operatorname{Solar}(t)$ is an appropriate time series representative of solar irradiance or spectral irradiance; N3.4 is the Niño-3.4 index (defined as the SST anomaly averaged over the $5^{\circ} \mathrm{S}-5^{\circ} \mathrm{N}$ and $120^{\circ}-170^{\circ} \mathrm{W}$ sector; $\operatorname{lag}_{\text {ENSO }}$ is a lag time required to produce a maximum correlation amplitude between $X(t)$ and N3.4; and $t^{\prime}=0$ for $t<t_{0}$ and $t^{\prime}=t-t_{0}$ for $t \geq t_{0}$, where $t_{0}$ is the time when a change of linear trend is assumed to occur (Reinsel et al. 2005). The coefficients $\beta_{\text {trend }}, \beta_{\mathrm{QBO} 1}, \beta_{\mathrm{QBO} 2}, \beta_{\text {volcanic }}, \beta_{\text {solar }}$,

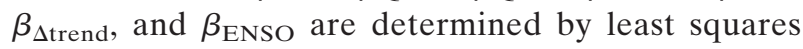
regression.

To estimate uncertainties in the regression coefficients and to account for autocorrelation of the residuals (data minus statistical model), we also use an improved procedure here relative to that employed in our previous work (e.g., Hood et al. 2010). This method has been developed in detail by Tiao et al. (1990) and has also been outlined more recently by Garny et al. (2007). In general, standard methods for estimating uncertainties in regression coefficients assume that the residuals are normally distributed about a zero mean and are not a function of time (i.e., they are white noise). However, even after all important explanatory variables ("basis functions") have been identified and included in the statistical model, the residuals are often autocorrelated and therefore do not completely satisfy these criteria. It is therefore necessary to adjust both the modeled observations and the basis functions to ensure that the residuals are approximately white noise. This is done by first determining the autoregression coefficient $\rho$ of the residuals, assuming that they can be represented as a first-order autoregressive process. Next, the observed 
time series and all basis functions are transformed as follows: $x(t) \rightarrow x(t)-\rho x(t-1)$, where $x(t)$ is a value at time $t$ and $x(t-1)$ is the value at the previous observation time (e.g., month or season). Then, the statistical model (1) is rerun on the transformed observed time series and basis functions. Finally, the regression coefficient variance can be determined from (e.g., von Storch and Zwiers 2002)

$$
\sigma_{\beta_{k}}^{2}=\frac{\chi^{2}}{N-M}\left[\left(\mathbf{X}^{\mathrm{T}} \mathbf{X}\right)^{-1}\right]_{k k},
$$

where $\sigma_{\beta_{k}}$ is the standard deviation for the $k$ th regression coefficient, $\chi^{2}$ is the sum of the squared residuals, $N$ is the number of observations, $M$ is the number of fitted coefficients, and $\mathbf{X}$ is the matrix of basis functions.

For analyses of data records covering the period when continuous global satellite measurements are available (1979-2009), we use $u_{30 \mathrm{hPa}}$ and $u_{10 \mathrm{hPa}}$ based on the dataset compiled originally by Barbara Naujokat at the Free University of Berlin (available from http://www. geo.fu-berlin.de/en/met/ag/strat/produkte/qbo). We follow Steinbrecht et al. (2003) in using actual QBO equatorial winds at the 30- and 10-hPa levels to account for QBO variability. Winds at these levels are about one-quarter cycle out of phase so they can be treated as approximately independent variables. Unlike Hood et al. (2010), we do not allow for a phase lag of the QBO winds relative to the observational time series. We have tested this QBO representation against other similar representations [e.g., the orthogonal time series of Randel and Wu (1996)] and find that it is adequate for the purpose of estimating solar regression coefficients. Also, for the post-1979 period, Aerosol $(t)$ in (1) is based on a combination of Stratospheric Aerosol Measurement (SAM) II and Stratospheric Aerosol and Gas Experiment (SAGE) I/II optical depth measurements (Thomason et al. 1997) while $\operatorname{Solar}(t)$ is the Mg II solar UV index, defined as the core-to-wing ratio of the solar $\mathrm{Mg}$ II line at $280 \mathrm{~nm}$ based on Nimbus 7 SBUV, National Oceanic and Atmospheric Administration (NOAA)-9 and -11 SBUV/2, and Upper Atmosphere Research Satellite (UARS) Solar Ultraviolet Spectral Irradiance Monitor (SUSIM) data (e.g., Viereck and Puga 1999). N3.4 is obtained online (from http://www.cgd. ucar.edu/cas/catalog/climind/Nino_3_3.4_indices.html). A change of linear trend is assumed to occur at a time $t_{0}$ of January 1996, following the suggestion of Reinsel et al. (2005) and based on inspection of Fig. 1. However, we have tried using alternate values for $t_{0}$ to \pm 3 years and find that the solar regression results are not sensitive to the exact choice for $t_{0}$ in this range.

Application of the MLR model (1) and uncertainty estimation procedure outlined above to seasonal mean SAGE II ozone profile data shows that there is only
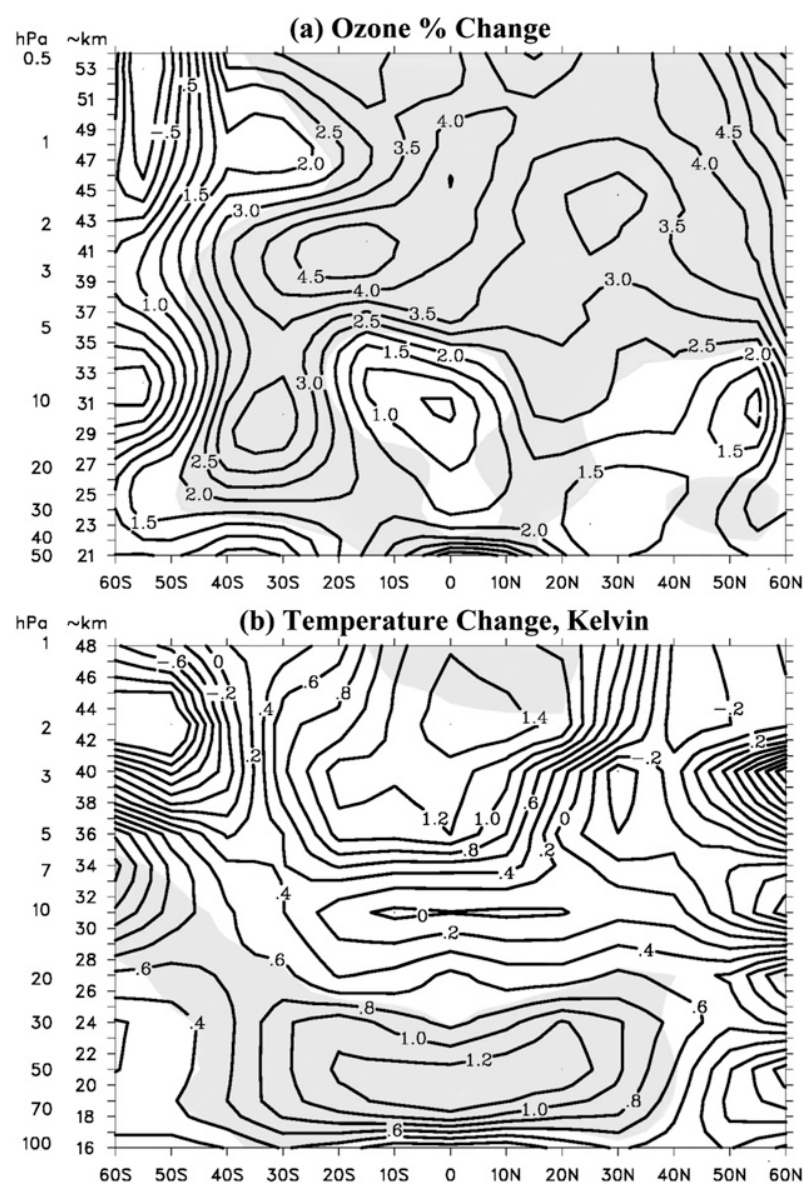

FIG. 2. Annual mean solar cycle regression coefficient (change from solar minimum to maximum) for (a) SAGE II ozone profile data over the December 1984-August 2003 period and (b) ERA-40 reanalysis temperature data over the 1979-2001 period. Shaded areas are significant at the $2 \sigma$ (95\% confidence) level. Note the different vertical scales.

relatively weak autocorrelation for this dataset, apparently reflecting the limited spatial sampling of this solar occultation instrument. The annual mean solar regression coefficients for zonal mean SAGE II ozone are shown in Fig. 2a for the 1979-2003 period. The coefficients are expressed as the change from solar minimum to maximum, assumed to be equivalent to an increase in the Mg II index by 0.0169 units. These coefficients and estimated uncertainties are very similar to those obtained previously for the same time period (Soukharev and Hood 2006; Randel and Wu 2007). Similar application of the MLR model to SAGE II data through August 2005 (the latest available data) shows that the lower-stratospheric response is weakened somewhat, especially in the NH. This may reflect a weaker solarinduced decrease of ozone during the descending phase of solar cycle 23, as seen also in Fig. 1a (see section 5). 
(a) Annual Mean Column Ozone \% Change, Solar Max - Min, 1979-2009

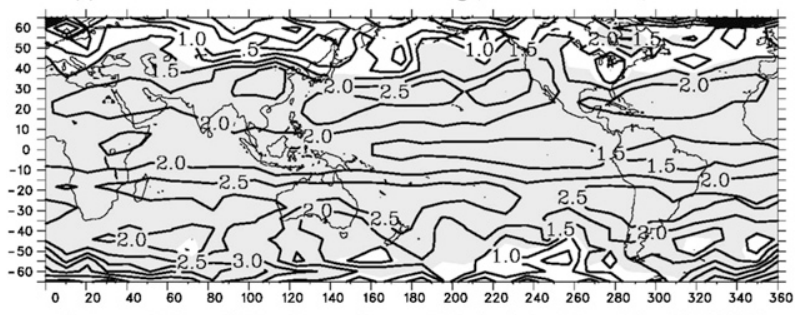

(b) Annual Mean 50 hPa Temp. Change, Kelvin, Solar Max - Min, 1979-2009

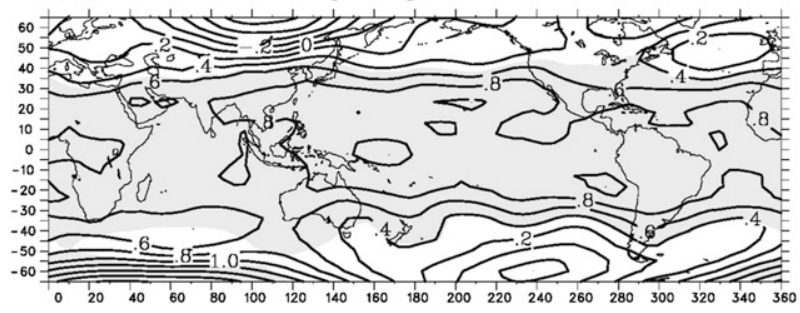

FIG. 3. Annual mean solar cycle regression coefficients (change from solar minimum to maximum) for (a) column ozone using version 8 TOMS/SBUV data over the 1979-2009 period and (b) 50-hPa temperature using NCEP-NCAR reanalysis data over the same time period. Shaded regions indicate statistical significance at the $2 \sigma$ level.

Application of the MLR procedure to 40-yr European Centre for Medium-Range Weather Forecasts (ECMWF) Re-Analysis (ERA-40) temperature data over the 19792001 period shows that there is stronger autocorrelation for this dataset, especially in the upper stratosphere where autocorrelation coefficients for the residuals after initial application of the statistical model are as large as 0.7. The annual mean solar regression coefficients after correcting for autocorrelation are shown in Fig. 2b and are qualitatively similar to those obtained by other authors (e.g., Shibata and Deushi 2008; Frame and Gray 2010). Comparing the temperature response of Fig. $2 b$ to the ozone response of Fig. 2a, it is seen that the extension of the lower-stratospheric ozone response to higher latitudes is repeated also in the temperature response. Also, the temperature response is statistically significant at altitudes as low as $16 \mathrm{~km}$ in the southern subtropics. Because of interference from volcanic aerosols in the SAGE ozone retrievals (Wang et al. 1996), the SAGE measurements are unreliable at altitudes less than approximately $21 \mathrm{~km}$. The reanalysis temperature data (either ERA-40 or NCEP-NCAR) therefore provide a useful check on the existence and properties of the lower-stratospheric response. However, this check is only possible over the 1979-2001 period for the ERA-40 data considered here. As will be seen in section 5 , there is evidence that the lower-stratospheric response was significantly weakened during the last half of the 1979-2009 period.

Application of the MLR model to TOMS/SBUV column ozone and NCEP-NCAR reanalysis $50-\mathrm{hPa}$ (a) DJF Column Ozone \% Change, Solar Max - Min, 1979-2009

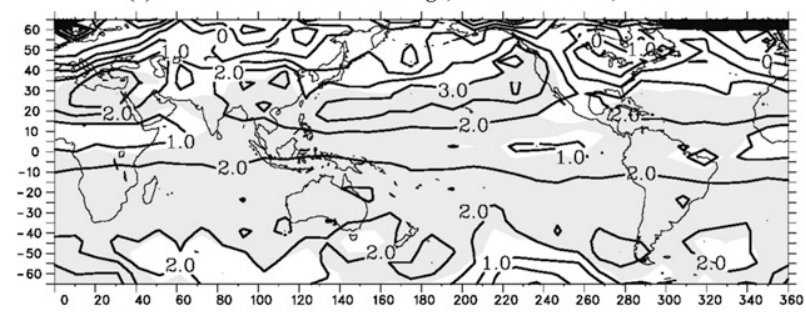

(b) DJF 50 hPa Temperature Change, Kelvin, Solar Max - Min, 1979-2009

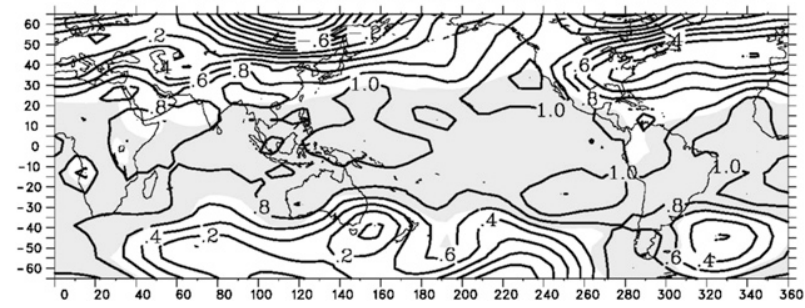

FIG. 4. NH winter (DJF) solar cycle regression coefficients for (a) column ozone and (b) $50-\mathrm{hPa}$ temperature. Format is as in Fig. 3.

temperature data over the 1979-2009 period yields solar regression coefficients shown in Figs. 3, 4, and 5 for the annual mean, $\mathrm{NH}$ winter, and $\mathrm{NH}$ summer, respectively. The 50-hPa level is chosen because it lies near the level of maximum ozone concentration at middle latitudes and because temperature at this level has previously been found to correlate well with column ozone variability on decadal time scales (e.g., Steinbrecht et al. 2003). For both column ozone and 50-hPa temperature, significantly positive regression coefficients are obtained mainly at low to middle latitudes. The seasonal coefficients of Figs. 4 and 5 exhibit a slight asymmetry toward the summer hemisphere for both ozone and

(a) JJA Column Ozone \% Change, Solar Max - Min

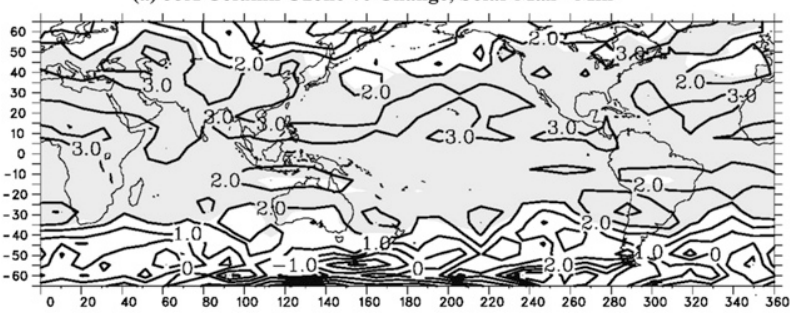

(b) JJA 50 hPa Temperature Change, Kelvin, Solar Max - Min

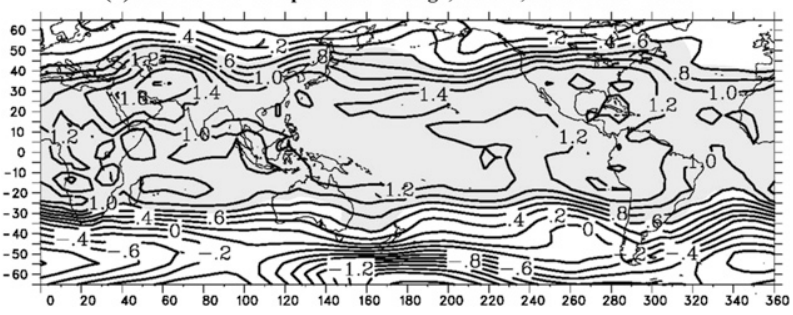

FIG. 5. As in Fig. 4, but for the NH summer (JJA) season. 
temperature. Note that there is at least a weak correlation between regional column ozone and $50-\mathrm{hPa}$ temperature responses during $\mathrm{NH}$ winter (Fig. 4). For example, a positive response of both variables is obtained off the West Coast of the United States in boreal winter and responses are both weak in the equatorial eastern Pacific. Finally, there is a definite tendency for the column ozone regression coefficients to have smaller amplitudes at tropical latitudes than at subtropical latitudes in Figs. 3-5. The origin of this tendency is discussed further in section 5 .

The similar latitude and seasonal dependences of column ozone and 50-hPa temperature solar regression coefficients provides further evidence that most of the column ozone response occurs in the lower stratosphere (where the $50-\mathrm{hPa}$ level is centered). In addition, the location of the zone of maximum response at low to subtropical latitudes and the asymmetry toward the summer hemisphere for both December-February (DJF) and June-August (JJA) suggests an origin involving a solar modulation of the BDC because the upwelling branch of the BDC is limited to low and subtropical latitudes and is also shifted somewhat toward the summer hemisphere. It is known, for example, that warm ENSO (El Niño) events accelerate the BDC with an associated increase in tropical upwelling, resulting in negative ozone and temperature responses in the tropical lower stratosphere (e.g., Calvo et al. 2010; Hood et al. 2010). To produce positive tropical ozone and temperature responses near solar maxima, a deceleration at that time of the BDC would be required, similar to that which occurs, on average, during La Niña events.

As shown by Gray et al. (2009) using a fixed dynamical heating $(\mathrm{FDH})$ model, the observed lower-stratospheric temperature response is at least partly a radiative consequence of the observed lower-stratospheric ozone response. However, the observationally derived temperature responses at $50 \mathrm{hPa}$ shown in Figs. 2b, 3b, 4b, and 5b are higher in amplitude than that estimated by the FDH model $(\sim 0.8-1.2 \mathrm{~K}$ vs $\sim 0.4 \mathrm{~K})$. This could be partly due to an underestimation of the lower-stratospheric ozone response that was used in the FDH calculation (based on SAGE I and II data, whose retrievals are affected by volcanic aerosols at the lowest levels). But it also reflects an additional advective component of the temperature response produced by the solar-induced modulation of the tropical upwelling rate. The apparent regional responses shown in the figures further suggest that the decadal variation of upwelling rate is locally variable.

It should be noted that the MLR solar regression coefficients plotted in Figs. 2-5 are, in effect, averaged over both phases of the QBO. Labitzke $(2004,2007)$ has shown that separation of stratospheric data by QBO phase can enhance the solar signal and that the solar signal is generally stronger during the east QBO phase than during the west phase as monitored near $45 \mathrm{hPa}$. It is possible in principle to carry out an MLR analysis using data that are preseparated by QBO phase in order to determine the solar cycle ozone and temperature response for each QBO phase [see, e.g., Figs. 7 and 8 of Steinbrecht et al. (2003)]. Such an analysis is beyond the scope of the present study. However, a weakening of the BDC (and possibly also the Hadley circulation) near solar maxima is necessary to explain the observed temperature response at low latitudes during the QBO-east phase (Labitzke 2004, 2007). Since the solar signal during the east phase is dominant at these latitudes, it follows that the tropical upwelling rate averaged over both QBO phases is weaker, on average, near solar maxima.

For comparison to the observationally derived zonal mean ozone and temperature solar regression coefficients of Fig. 2, Fig. 6 shows results of a similar MLR analysis of zonal mean model data from a simulation using a chemistry climate model coupled to a troposphereocean model (K. Matthes and C. Blume 2010, personal communication). The chemistry-climate model is the Whole Atmosphere Community Climate Model, version 3 (WACCM3) and the troposphere-ocean model is the Community Climate System Model, version 3 (CCSM3). This transient simulation is similar to that described by Meehl et al. (2009; see supporting online material) with WACCM3 coupled to the dynamical ocean, land, and sea ice components of CCSM3. However, the transient simulation considered here (designed by $\mathrm{K}$. Matthes and F. Sassi) also includes a prescribed QBO wind oscillation with equatorial zonal winds in the model relaxed toward idealized QBO winds as described by Matthes et al. (2010).

Considering first the model ozone regression coefficients of Fig. 6a, there are a number of qualitative similarities to the observational coefficients of Fig. 2a: The largest amplitudes are found in the upper stratosphere; there is a relative minimum in the equatorial middle stratosphere; and there is a second smaller response maximum in the tropical lower stratosphere. The upperstratospheric ozone maximum for the model is centered near the 3-4-hPa level and has a peak amplitude of approximately $2.5 \%$, decreasing to less than $1 \%$ above the stratopause except at latitudes less than $20^{\circ}$. The ozone response derived from SAGE II data also peaks near $3 \mathrm{hPa}$ but has a peak amplitude of approximately $4.5 \%$, decreasing only slowly with increasing altitude. The modeled ozone relative response minimum in the middle stratosphere is a consequence of the prescribed QBO because it is not present when model data are analyzed from a simulation without an imposed QBO. The fact 

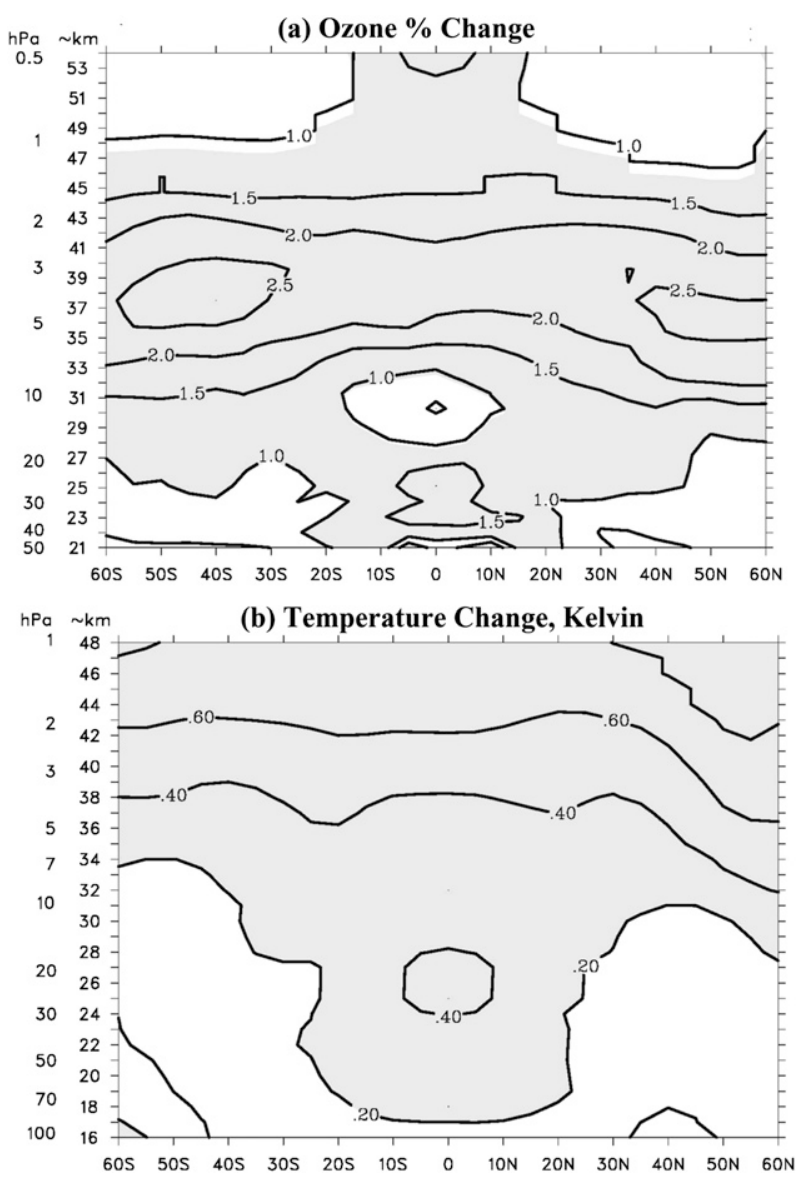

FIG. 6. Annual mean solar cycle regression coefficients (change from solar minimum to maximum) as calculated from model data for a simulation using WACCM3 coupled to CCSM3, including a prescribed QBO. (a) The model ozone profile solar coefficient. (b) The model temperature regression coefficient. Regions with ozone percentage change of more than about $1 \%$ and with temperature change of more than $0.2 \mathrm{~K}$ are shaded for emphasis. Note the different vertical scales.

that the observed ozone response minimum (Fig. 2a) is also centered on the equator near the same altitude is therefore strong evidence that this minimum is at least partly a consequence of the QBO. The observed ozone response minimum may be due either to a solar modulation of QBO winds (e.g., McCormack et al. 2007) or to aliasing from a QBO in which one phase happens to dominate near solar maxima during a limited observational period (e.g., Lee and Smith 2003). It is therefore not likely to be due only to relative downwelling near solar maxima, as proposed by Hood et al. (2010) from a comparison with ENSO ozone coefficients. As will be seen in section 4 below, the ENSO ozone coefficient (Fig. 10a) has a secondary response in the middle stratosphere that is opposite in sign to that in the lower stratosphere but the ENSO response is not centered exactly on the equator. The model ozone solar response of Fig. 6a also shows a secondary response maximum in the tropical lower stratosphere that is mainly a consequence of the prescribed QBO in the model. However, the response is limited to latitudes less than about $20^{\circ}$, as expected from the zonal mean wind relaxation applied in the model, which extended from $22^{\circ} \mathrm{S}$ to $22^{\circ} \mathrm{N}$. It does not extend to higher middle latitudes as seen in the SAGE result of Fig. 2a.

Considering next the zonal mean temperature model solar regression coefficients of Fig. 6b, the model solar response is largest in the upper stratosphere $(0.6-0.8 \mathrm{~K}$ from solar minimum to maximum) and generally decreases with decreasing altitude. For comparison, the upper-stratospheric temperature response estimated from ERA-40 data is also largest in the upper stratosphere but has a somewhat larger amplitude of up to $1.4 \mathrm{~K}$ near the equatorial stratopause. A small secondary model response maximum is present in Fig. $6 \mathrm{~b}$ in the equatorial lower stratosphere with an amplitude of about $0.5 \mathrm{~K}$. This maximum is also probably a consequence of the prescribed QBO since it is limited to latitudes less than $10^{\circ}$. For comparison, the response estimated from ERA-40 data (Fig. 2b) has a larger amplitude of 0.4$1.3 \mathrm{~K}$ and extends over a wider latitude range in the lower stratosphere down to altitudes as low as 16 or $17 \mathrm{~km}$. This observed temperature response in the lower stratosphere is consistent in latitude dependence with zonal mean ozone solar regression coefficients derived from either SAGE II data (Fig. 2a) or SBUV(/2) data (Soukharev and Hood 2006). Finally, the minimum in the observationally estimated temperature solar coefficient seen in Fig. $2 b$ at about $31 \mathrm{~km}$ altitude is not simulated in the model.

Overall, while the model simulation results of Fig. 6 verify a role for the $\mathrm{QBO}$ in producing some of the vertical structure in the observational results of Fig. 2 in the tropical middle and lower stratosphere, the observed zonal mean solar response in the lower stratosphere has a higher amplitude and extends to higher latitudes and lower altitudes than is simulated in the model. This difference is most easily attributed to an increase in the relative downwelling rate (e.g., weaker BDC) at solar maximum compared to solar minimum that is not fully simulated in the model. Moreover, as discussed above in relation to Figs. 3-5, the latitude and seasonal dependences of the lower-stratospheric ozone and temperature responses (asymmetry toward the summer hemisphere) strongly suggest a role for the BDC in producing these responses. Plots of the model column ozone and $50-\mathrm{hPa}$ temperature solar regression coefficients have also been produced and do not show the amplitudes and summer hemisphere asymmetries that are seen in the observational results of Figs. 3-5. It is therefore concluded that a solar-induced modulation of the BDC probably existed 
during the observational period that was not fully reproduced in the WACCM3/CCSM3 simulation.

However, we emphasize that WACCM3 has recently been upgraded to WACCM4, which now self-consistently includes coupled ocean, sea ice, and land components (Marsh 2010). Moreover, WACCM4 has been more carefully validated against observations than was the case for the WACCM3/CCSM3 coupled simulations. It will therefore be of interest to compare the observational results against the WACCM4 simulation results as they become available. This will be the subject of future work.

\section{Decadal variations of extratropical wave forcing}

One approach toward investigating whether decadal variations of the BDC may exist that could contribute to solar-induced variations in the tropical and subtropical lower stratosphere is to evaluate decadal variations of planetary-scale wave forcing. The latter is known to be an important driver of the BDC (e.g., Holton et al. 1995). We have previously investigated the existence of such decadal variability (Hood and Soukharev 2003, hereafter HS03). Here we extend the analysis in time and evaluate further whether BDC decadal variability is sufficient to explain much of the observed decadal ozone variation of Fig. 1a.

Although the BDC is apparently driven by planetary wave drag occurring mainly at subtropical latitudes (Plumb and Eluszkiewicz 1999; Semeniuk and Shepherd 2001), the planetary wave flux monitored near the climatological maximum at higher latitudes $\left(60^{\circ}-70^{\circ}\right)$ in the winter hemisphere is known empirically to correlate closely with the strength of the tropical upwelling rate (Randel 1993; HS03). On short time scales (e.g., following stratospheric sudden warmings), an approximate inverse linear relationship is observed between zonally averaged meridional eddy heat flux $\overline{v^{\prime} T^{\prime}}$ (approximately proportional to the vertical component of the EliassenPalm (E-P) planetary wave flux), as monitored for example at $60^{\circ} \mathrm{N}, 20 \mathrm{hPa}$ in winter, and ozone tendencies (or temperature tendencies) in the tropical lower stratosphere. Figure 11 of HS03 shows a linear regression analysis of daily tropical column ozone and temperature tendencies versus $\overline{v^{\prime} T^{\prime}}$ at $60^{\circ} \mathrm{N}, 20 \mathrm{hPa}$ using data for five winters (November-March 1979/80-1983/84). For column ozone, the estimated sensitivity can be expressed as $\left(d \overline{\mathrm{O}_{3}} / d t\right)_{20 \mathrm{SN}} \simeq A_{N} \overline{v^{\prime} T^{\prime}}$, where $A_{N}=-0.0031 \pm 0.0002$ Dobson units (DU) day ${ }^{-1}\left(\mathrm{~K} \mathrm{~m} \mathrm{~s}^{-1}\right)^{-1}$ and the daily column ozone tendencies have been averaged over $20^{\circ} \mathrm{S}-$ $20^{\circ} \mathrm{N}$. A similar analysis using daily column ozone tendencies averaged over $35^{\circ} \mathrm{S}-35^{\circ} \mathrm{N}$ yields $A_{N}=-0.0027 \pm$ $0.0002 \mathrm{DU}_{\text {day }}{ }^{-1}\left(\mathrm{~K} \mathrm{~m} \mathrm{~s}^{-1}\right)^{-1}$.
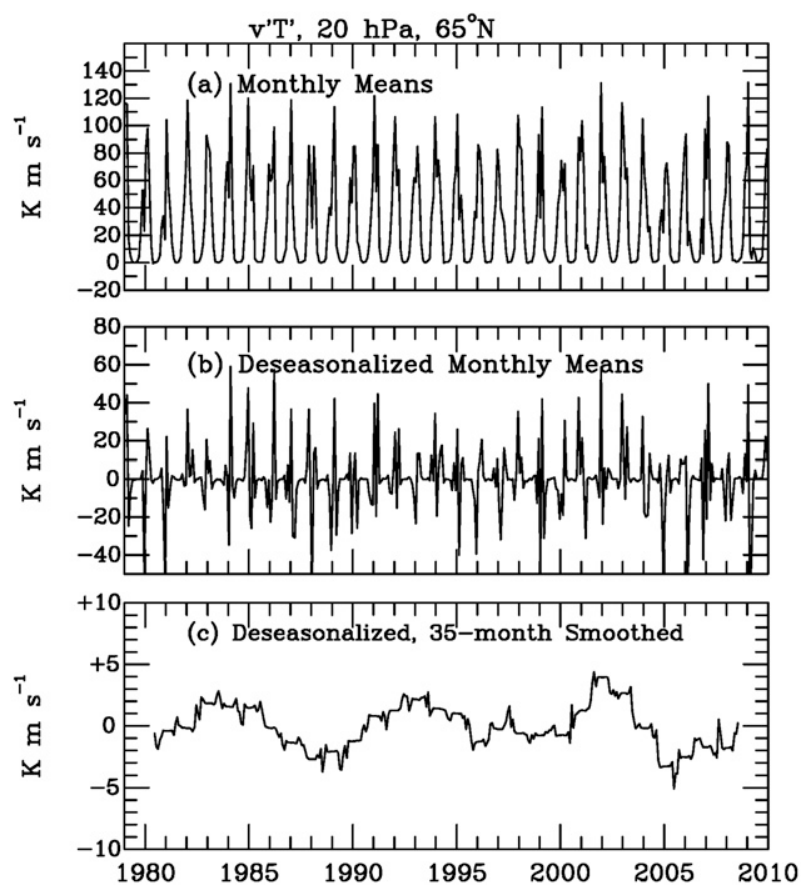

FIG. 7. Time series of monthly mean eddy heat flux at $65^{\circ} \mathrm{N}$, $20 \mathrm{hPa}$, calculated from daily NCEP-NCAR reanalysis data: (a) monthly means, (b) deviations from long-term monthly means, and (c) result of applying a 35-month boxcar filter to the deseasonalized monthly means.

In the case of ozone, the reason for such a linear relationship follows from a simplified form of the ozone continuity equation (Randel et al. 2002a; Andrews et al. 1987):

$$
\frac{\partial \bar{\chi}}{\partial t} \simeq-\bar{w}^{*} \bar{\chi}_{z}-\left(\bar{\chi}-\bar{\chi}_{\mathrm{eq}}\right) / \tau_{c}
$$

where $\bar{\chi}$ is zonal mean ozone mixing ratio, $\bar{w}^{*}$ is the transformed Eulerian mean vertical velocity, $\bar{\chi}_{z}$ is the vertical gradient of ozone mixing ratio, $\bar{\chi}_{\text {eq }}$ is a chemical equilibrium value for $\bar{\chi}$, and $\tau_{c}$ is the odd oxygen lifetime. For short-term events (i.e., events occurring on time scales much shorter than $\tau_{c}$ ), (3) reduces to $\partial \bar{\chi} / \partial t \simeq-\bar{w}^{*} \bar{\chi}_{z}$. Or, if $\bar{w}^{*}$ in the tropical lower stratosphere is dominantly determined by extratropical wave forcing as monitored at $60^{\circ} \mathrm{N}$, then $\partial \bar{\chi} / \partial t \propto-\overline{v^{\prime} T_{60 \mathrm{~N}}^{\prime}}$.

As shown in Fig. 7, some evidence exists for a decadal variation of extratropical wave forcing in the NH. Figure 7 a plots monthly means of daily eddy heat flux calculated using NCEP-NCAR reanalysis data at $65^{\circ} \mathrm{N}$, $20 \mathrm{hPa}$ over the 1979-2009 period. The chosen latitude is near that of the climatological maximum of $\mathrm{NH}$ eddy heat flux (see Fig. 8 of HS03). As discussed by HS03, the meridional eddy heat flux is a highly derived quantity and reanalysis datasets may not provide perfect 
measurements. Nevertheless, these data in principle provide a useful means for evaluating long-term variability of the wave forcing and, by implication, of the BDC. As seen in Fig. 7a, the eddy heat flux peaks each year in $\mathrm{NH}$ winter with an amplitude that varies from year to year. Figure $7 \mathrm{~b}$ shows the same data after subtracting the long-term monthly means for each month. The deseasonalized eddy heat fluxes again show significant interannual and longer-term variations. Finally, Fig. $7 \mathrm{c}$ shows 35-month running averages of the deseasonalized monthly eddy heat fluxes at this location.

At least up until about 2000, a decadal variation can be seen in the long-term running averages of Fig. $7 \mathrm{c}$ with maxima centered near 1984 and 1993 and minima centered near 1988 and 1998. Since solar maxima during this period occurred near 1980,1990, and 2001, the peaks in wave forcing tended to occur near and approaching solar minima while the wave-forcing troughs occurred near and approaching solar maxima. For sufficiently long ozone lifetimes, the phase of this variation is approximately that expected if this is a major forcing of the 11-yr ozone variation in the tropics. Specifically, when the wave forcing is high (as in 1982-85), the observed long-term ozone tendency is negative. When the wave forcing is low (as in 1986-88), the long-term ozone tendency is positive, and so on. On the other hand, during the last 10 or $15 \mathrm{yr}$ of the record, the phase of the long-term variation of the 35 -month running averages is not very consistent with that seen during the first $15 \mathrm{yr}$ of the record. In particular, a distinct minimum occurs in 2005 near or approaching solar minimum conditions. Also, the minimum near 1998 was not as deep as that in 1988. A more quantitative analysis is therefore needed to evaluate the extent to which decadal variations of wave forcing can contribute to the observed column ozone record at low latitudes.

For this purpose, it is necessary to consider the full continuity equation (3), including the relaxation term that depends on the ozone lifetime. For the present application, to first order, (3) may be rewritten in the form

$$
\frac{d \overline{\mathrm{O}}_{3}}{d t} \simeq A_{N} \overline{v^{\prime} T_{60 \mathrm{~N}}^{\prime}}-\overline{\mathrm{O}_{3}} / \tau_{c}
$$

where $A_{N}$ is a regression coefficient derived from observations of short-term deviations, $\overline{\mathrm{O}_{3}}$ is the approximate ozone column in the tropical lower stratosphere, and all variables represent deviations from equilibrium values at $t=0$. In particular, if $\overline{\mathrm{O}_{3}}$ is averaged over $35^{\circ} \mathrm{S}-$ $35^{\circ} \mathrm{N}$, we use $A_{N} \simeq-0.0027 \mathrm{DU}$ day $^{-1}\left(\mathrm{~K} \mathrm{~m} \mathrm{~s}^{-1}\right)^{-1}$.

The odd oxygen lifetime in the tropical lower stratosphere ranges from about 100 days near $20 \mathrm{hPa}$ to about 400 days near $50 \mathrm{hPa}$ and about 800 days near $100 \mathrm{hPa}$ (e.g., Brasseur and Solomon 2005). For the purpose of

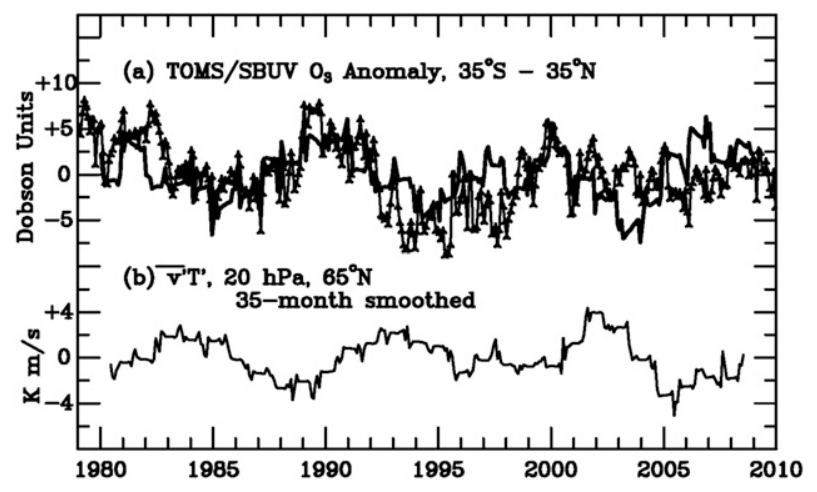

FIG. 8. (a) The thick line is calculated using (4) together with the deseasonalized monthly mean eddy heat flux data at $65^{\circ} \mathrm{N}, 20 \mathrm{hPa}$ shown in Fig. 7b, as described in the text. (b) 35-month smoothed deseasonalized eddy heat fluxes, also shown in Fig. 7c.

a first-order analysis, we assume here that the effective lifetime is about 800 days (i.e., the lifetime in the lowermost stratosphere). Integrating (4) forward in time with this value for $\tau_{c}$ and using the (unsmoothed) observed monthly deviations of eddy heat flux at $60^{\circ} \mathrm{N}$, $20 \mathrm{hPa}$, the estimated decadal variation of total ozone in the tropics can be calculated (see the superposed thick line in Fig. 8a). We have neglected here wave forcing in the SH extratropics. HSO3 included an estimated contribution from the latter source. However, as emphasized, for example, by Randel et al. (2002b), eddy heat fluxes in the $\mathrm{SH}$ are much less reliable because of the paucity of radiosonde stations near $60^{\circ} \mathrm{S}$. We have therefore elected to show here only the NH contribution, which is larger than that in the SH because of larger planetary wave amplitudes.

Although the model is simplified and the eddy heat flux data are imperfect, this calculation at least suggests that some of the amplitude and phase of the tropical total ozone variation could be caused by decadal variations of extratropical wave forcing in the NH. However, as noted above, the phase of the time-averaged wave forcing variation changes after about 1995-2000. As seen in Fig. 8a, although the ozone maximum near 2000 is approximately matched, the overall fit of the model to the ozone data is generally poorer after this time. Assuming that the NH eddy heat flux data are accurate at this latitude, this implies that any solar-induced modulation of extratropical wave forcing and the BDC was not as effective after this time.

\section{MLR analysis of Hadley Centre SLP data}

Results of the previous two sections suggest that a solar-induced decadal modulation of the BDC may have existed that would help to explain the unexpectedly 
large response of lower-stratospheric ozone and temperature to 11-yr solar forcing, at least during solar cycles 21 and 22. While a solar-modulated QBO may contribute to producing the observed vertical structure of the response in the tropics (Fig. 6a), this mechanism alone is not able to explain the amplitude and latitudinal extent of the lower-stratospheric response. As discussed in the introduction, there are two remaining end-member physical mechanisms for explaining how solar variability could produce a solar-modulated BDC. First, there is the top-down mechanism in which direct UV forcing of the upper stratosphere perturbs ozone, radiative heating, zonal winds, and planetary wave propagation, thereby modulating the BDC (Kodera and Kuroda 2002; Nathan and Cordero 2007). Second, there is the bottom-up mechanism in which feedbacks from an ocean-troposphere response to solar variability modify planetary wave amplitudes in the troposphere, which in turn modulate the BDC. In reality, these mechanisms are not mutually exclusive since downward dynamical effects of the stratospheric response can partly drive the troposphere-ocean response, in addition to direct forcing by TSI variations (Haigh 1996, 1999; Balachandran et al. 1999; Shindell et al. 1999, 2006; Matthes et al. 2006; van Loon et al. 2007; Meehl et al. 2009; Meehl and Arblaster 2009; Bal et al. 2011). We therefore attempt to characterize further the troposphere-ocean response in this section to evaluate its possible relationship to the lower-stratospheric response.

Analyses of long-term SLP datasets to investigate the solar contribution to surface climate variability have previously been reported by a number of authors. Christoforou and Hameed (1997) analyzed historical data over the 1900-94 period for the strength and position of the Aleutian low and the position of the Hawaiian high during December and January. The data were composited for years of maximum and minimum solar activity, defined using annual mean sunspot number. It was found that the Aleutian low was on average weakened by about $1.6 \mathrm{hPa}$ and shifted about $10^{\circ}$ westward while the Hawaiian high was shifted about $1.6^{\circ}$ northward for solar maximum years relative to solar minimum years. Van Loon et al. (2007) reported a composite mean difference (CMD) analysis of Hadley Centre SLP data for January and February over the 1871-1998 period, again using annual mean sunspot number to define peak solar years. It was found that the Aleutian low was significantly weakened and shifted westward during peak solar years, qualitatively consistent with the Christoforou and Hameed results. Roy and Haigh (2010) reported an MLR analysis of global Hadley Centre SLP data over the 1850-2004 period using sunspot number to define the solar independent variable in the regression model.
A statistically significant weakening by about $4 \mathrm{hPa}$ of the Aleutian low at solar maximum relative to solar minimum during $\mathrm{NH}$ winter (DJF) was found, again qualitatively consistent with the results of previous authors. In summary, statistically significant SLP responses were only obtained by most authors in the Pacific sector and consisted primarily of a weakening and westward shift of the Aleutian low.

Analyses of long-term SST datasets to evaluate the response to 11-yr solar forcing have also been reported by a number of authors but the results are much less consistent than for analyses of SLP data. White et al. (1997) originally analyzed two independent SST records available at that time covering most of the twentieth century using a cross-spectral technique and a filtered solar irradiance proxy. In both records, they found a positive SST response peaking several years after solar maxima with maximum amplitude in the tropical Pacific and a negative response in the western Pacific (see their Fig. 6). The pattern roughly resembled that observed during a warm ENSO (El Niño) event. Currently, two primary long-term SST datasets extending back to about 1850 are available. These are the Hadley Centre dataset (which can be obtained from http://hadobs.metoffice.com/ hadsst2; Rayner et al. 2006) and the NOAA Extended Reconstructed Sea Surface Temperature (ERSST) dataset (obtainable from http://www.esrl.noaa.gov/psd/; Smith and Reynolds 2003, 2004; Smith et al. 2008). The two datasets differ somewhat especially prior to the 1940s because of differences in correction and analysis procedures, but both datasets incorporate global satellite SST measurements since the early 1980s. Van Loon et al. (2007) and van Loon and Meehl (2008) analyzed the extended Hadley Centre data using a CMD approach in which years of peak sunspot number were chosen to define solar maxima. Computing differences relative to a $1950-79$ base period, they found a statistically significant La Niña-like response. Zhou and Tung (2010) analyzed the NOAA dataset, also using a CMD approach. They confirmed the van Loon et al. (2007) result when using years of peak sunspot number to define solar maxima but found that the response was less significant when solar peak years were determined using the TSI reconstruction of Lean et al. (1995) and Wang et al. (2005). When the whole available period (1854-2007) was analyzed to determine the baseline climatology, the response was not statistically significant. Roy and Haigh (2010) presented results of an MLR analysis of the NOAA dataset but using sunspot number to describe solar variability. Using this approach, they were not able to confirm the van Loon et al. (2007) result but instead found a weak and statistically insignificant El Niño-like response pattern. Tung and Zhou (2010) applied an MLR analysis to both the 
Hadley Centre and NOAA datasets using the LeanWang TSI reconstruction to represent solar variability. They found a weak and statistically insignificant warming in the equatorial eastern Pacific, consistent with the Roy and Haigh (2010) result, but could not say whether the pattern was El Niño-like or La Niña-like.

Based on the above review, while MLR analyses of available long-term SLP measurements have yielded reasonably consistent evidence for a solar-induced decadal response in the Pacific sector, this is not the case for SST data. We have also carried out preliminary MLR analyses of the Hadley Centre SST dataset that confirm the difficulty of extracting a consistent solar signal from SST data using the MLR method. For example, we have divided the SST dataset for the 1880-2009 period (130 yr) into approximately equal parts and have obtained inconsistent results for the solar regression coefficient for the two time periods. Possible explanations include the high interannual variability of SST's, especially in the eastern tropical Pacific, associated with ENSO variability, and errors in the SST measurements. It is well known that the SST measurements are subject to uncertainties, especially prior to about 1950 when the spatial coverage was reduced and when significant changes in measurement methods were implemented. For example, as pointed out by Thompson et al. (2008), a major discontinuity in global SST measurements occurred in 1945 because of a change in observations from dominantly U.S. ships during World War II, which used mainly engine room intake SST measurements, to about $50 \%$ by U.K. ships after World War II, which used mainly uninsulated bucket measurements.

We therefore focus in this section on further analysis of Hadley Centre SLP data. SLP is arguably a more relevant metric than SSTs for evaluating effects of the troposphere-ocean response on planetary wave forcing of the BDC, which is the main objective of this paper. For MLR analysis of the SLP data back to 1880, we use essentially the same statistical model (1) that was applied to analyze the stratospheric datasets in section 2, but with the addition of an explanatory term proportional to the Pacific decadal oscillation (PDO) index (PDOI). Specifically, a term is added to the right side of (1) of the form $+\beta_{\mathrm{PDO}} \operatorname{PDOI}(t)$, where $\operatorname{PDOI}(t)$ is the PDO index, defined as the leading principal component of monthly SST anomalies in the North Pacific poleward of $20^{\circ} \mathrm{N}$ (Zhang et al. 1997; Mantua et al. 1997; N. Mantua 2011, personal communication). Monthly values of the PDOI beginning in January 1900 were obtained online (from http://jisao.washington.edu/pdo/PDO.latest).

To extend our MLR analyses back to times as early as 1880 , other sources of data for $u_{30 \mathrm{hPa}}, u_{10 \mathrm{hPa}}, \operatorname{Aerosol}(t)$, Solar $(t)$, and N3.4 must be used. For $u_{30 \mathrm{hPa}}$ and $u_{10 \mathrm{hPa}}$, the Berlin data are only available back to 1953 . For earlier times, the best available data are the reconstructed QBO time series of Brönnimann et al. (2007) (S. Brönnimann 2011, personal communication). This reconstructed series extends back to 1908 with reasonable accuracy and is extrapolated to earlier times without observational constraints by repeating a "standard" QBO cycle plus an annual cycle. For Aerosol $(t)$, we use the long-term record compiled at the Goddard Institute for Space Studies (http://data.giss.nasa.gov/modelforce/ strataer). For Solar $(t)$, prior to 1979 , possible time series include the $10.7-\mathrm{cm}$ solar radio flux (available back to 1947), which is a close proxy for monthly and interannual solar UV flux, and sunspot numbers, available from the NOAA National Geophysical Data Center (ftp://ftp.ngdc. noaa.gov/STP/SOLAR_DATA/SUNSPOT_NUMBERS). Although sunspot numbers are a somewhat less reliable proxy for solar spectral irradiance than F10.7, they are available for the whole 1880-2009 time period. We therefore adopt sunspot numbers for $\operatorname{Solar}(t)$ when analyzing data over the 1880-2009 time period. Finally, for N3.4, we use monthly values computed within the $5^{\circ} \mathrm{S}-5^{\circ} \mathrm{N}$ and $120^{\circ}-170^{\circ} \mathrm{W}$ sector from the Hadley Centre SST record (HADISST1) (S. Brönnimann 2011, personal communication).

Figure 9a shows the calculated SLP solar regression coefficient for the NH winter season for the 1900-2009 period (during which PDOI data are available) and after correction for autocorrelation as described in section 2 . The MLR analysis was applied to time series at each grid point consisting of 110 seasonal (DJF) means. The residuals after an initial application of (1) were only weakly autocorrelated so the correction was minor. The two QBO terms were found to be unimportant for the analysis of the seasonal SLP data: Separate analyses with and without inclusion of the QBO terms yielded nearly identical results. But a similar comparison of separate analyses with and without including the PDO term shows that there are some small but significant changes when the PDO term is included. For example, the amplitude of the Aleutian solar response maximum is reduced somewhat when the PDO term is included. The change-of-trend term with $t_{0}$ near 1996 had only a very minor effect on the calculated solar coefficients, as would be expected. Nevertheless, the SLP residuals show a small change in slope near this time if the term is not included; therefore it is retained. Overall, we conclude that a statistical model that contains at least the following explanatory variables yields a reasonable representation of the SLP data: Trend, solar, volcanic, ENSO, PDO, and change of trend. However, if the analysis is carried out without a PDO term (as is necessary for data extending to times prior to 1900), the calculated solar regression coefficients are still approximately valid. 
(a) DJF Sea Level Pressure Change, hPa, Solar Max - Min, 1900-2009

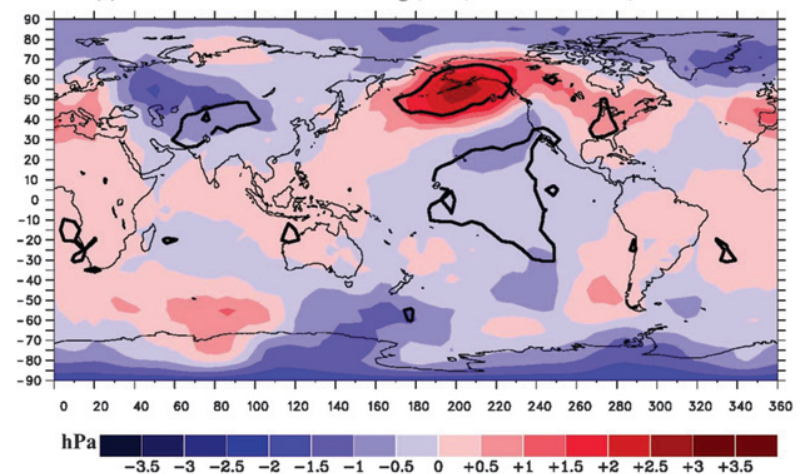

(b) DJF Sea Level Pressure Change, hPa, Per -1 Unit N3.4, 1900-2009

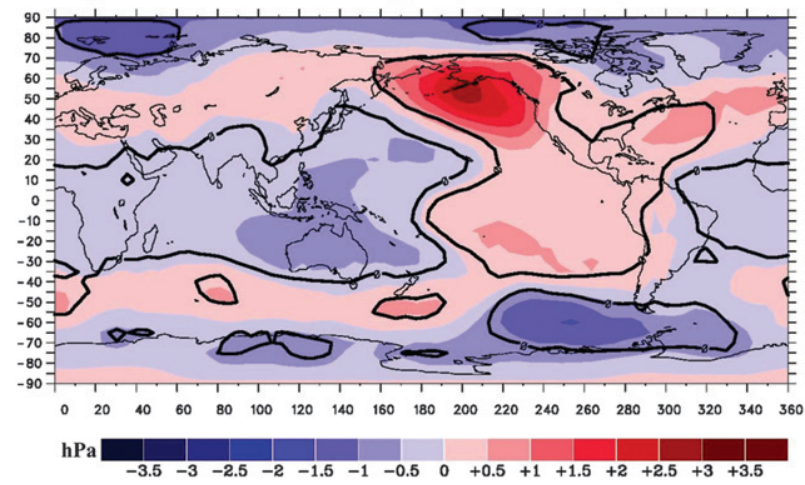

FIG. 9. (a) Sea level pressure solar regression coefficient for $\mathrm{NH}$ winter, calculated from Hadley Centre data over the 1900-2009 period, expressed as the change in $\mathrm{hPa}$ corresponding to an increase in sunspot number of 130 from solar minimum to maximum. (b) As in (a), but for the ENSO regression coefficient, expressed as the change in $\mathrm{hPa}$ for a -1-unit change in the Niño-3.4 index. Thick dark lines enclose regions where the coefficients are significant at the $2 \sigma$ level.

The solar regression coefficient results of Fig. 9a are comparable to those obtained by other analysts (e.g., Roy and Haigh 2010). The strongest significant response (enclosed by thick dark lines) is positive and is centered in the North Pacific (Aleutian) region. It has a mean peak amplitude of about $3 \mathrm{hPa}$ from solar minimum to maximum during the 1900-2009 period. A large zone of weaker negative significant response is also obtained in the central Pacific and a small zone of significant negative response is obtained in south-central Asia. Most of the Arctic region has a negative solar response, although it is not statistically significant. This, combined with the strong positive and significant Aleutian response, yields a pattern that resembles that of the Arctic Oscillation (AO). The North Atlantic Oscillation (NAO) index, defined as the difference in SLP between Lisbon, Portugal, and Reykjavik, Iceland, is also positive, as seen in the figure, though not formally significant. We emphasize that this response pattern is not repeated rhythmically every solar cycle. It is only the mean response averaged over many solar cycles. As discussed further in the next section, the response shows considerable cycle-to-cycle variability and is most clearly present during periods of relatively strong 11-yr solar variations.

We have also repeated the MLR analysis of Fig. 9a as a function of phase lag relative to the solar cycle. This is done by shifting the sunspot number time series in 1-yr increments to $\pm 5 \mathrm{yr}$. To fill in years beyond 2009 , we used known sunspot numbers for 2010 and extrapolated numbers based on previous solar cycles for 2011-14. It was found that the response amplitude near the approximate center of the response anomaly in the North Pacific $\left(\sim 55^{\circ} \mathrm{N}, 210^{\circ} \mathrm{E}\right)$ reaches a maximum amplitude near zero lag but there is a slight shift of the response toward negative lags (i.e., to 1 or $2 \mathrm{yr}$ preceding solar maximum). It is not clear whether this phase shift is statistically significant from zero. Nevertheless, this evidence for a slight negative phase shift of the peak response may be consistent with CMD analyses that find a maximum SLP response for years of peak sunspot number (e.g., van Loon et al. 2007) since sunspot peak years often occur 1 or $2 \mathrm{yr}$ prior to the center of the solar maximum period (Roy and Haigh 2010).

Figure $9 \mathrm{~b}$ shows the corresponding NH winter ENSO regression coefficient, expressed as the change in SLP for a -1 unit change in the Niño-3.4 index, corresponding to a moderate cold ENSO (La Niña) event [see, e.g., Fig. 2b of Hood et al. (2010) for a plot of the N3.4 time series]. Comparing Figs. 9a and 9b, the most clearly detected solar SLP response in the North Pacific (the positive anomaly centered in the Gulf of Alaska region) is very similar in location and amplitude to that which occurs on a shorter time scale during a moderate La Niña event. The observed 11-yr SLP response is therefore most simply characterized as "La Niña-like."

Figure 10 plots the annual mean ENSO regression coefficient for (a) zonal mean ozone as calculated from SAGE II data and (b) zonal mean temperature as calculated from ERA-40 data. The coefficients are again expressed as the change for a -1 unit change in the Niño-3.4 index. Ozone and temperature increases are seen to occur in the tropical lower stratosphere while an ozone decrease occurs in the middle stratosphere in the northern subtropics. It is generally well understood that these lower-stratospheric responses during a cold ENSO event are associated with decreases in the BDC, implying relative downwelling, which advectively increases ozone and temperature in the lower stratosphere where the ozone mixing ratio vertical gradient is positive and the ozone lifetime is long (e.g., Calvo et al. 2010; Randel et al. 2009b; Hood et al. 2010; Free and Seidel 2009).

According to a study by Garfinkel and Hartmann (2008), the North Pacific SLP anomaly that results from 
(a) SAGE II Ozone \% Change per -1 unit N3.4

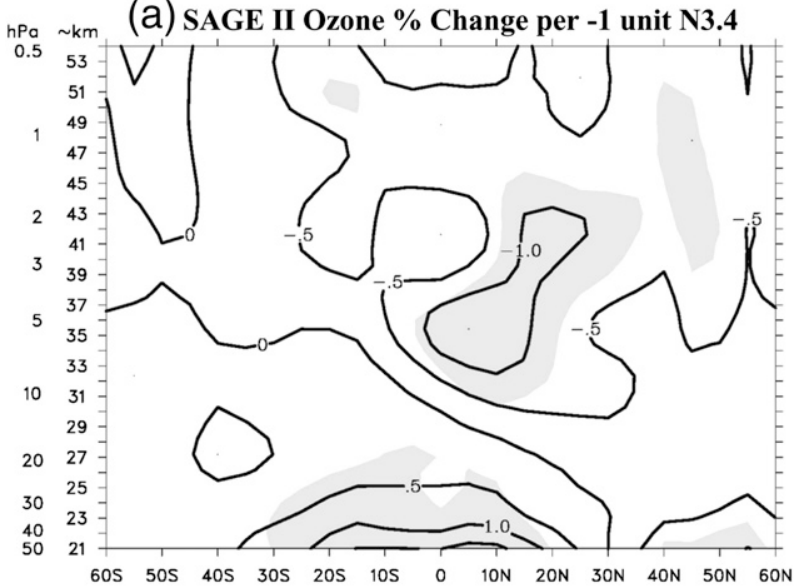

$\stackrel{h P a}{\sim} \sim \mathrm{km}$ (b) ERA-40 Temp. Change, Kelvin, per -1 unit N3.4

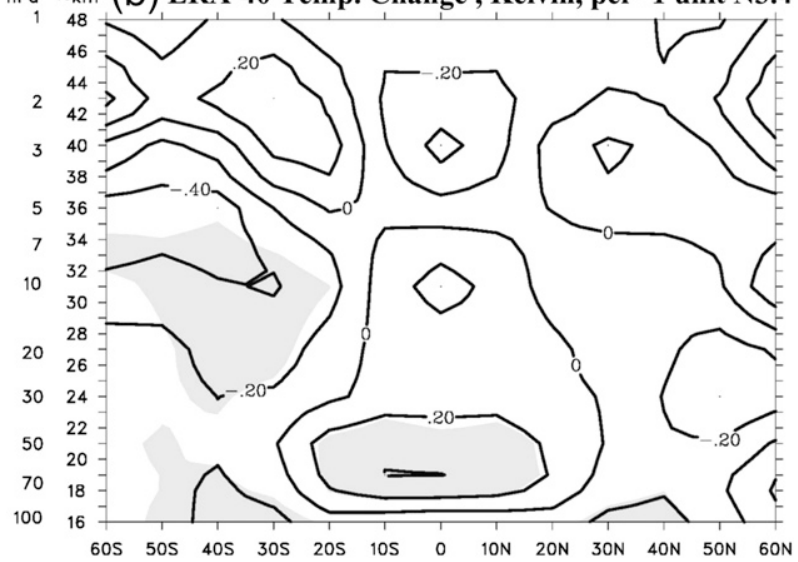

FIG. 10. Annual mean ENSO regression coefficients for (a) SAGE II ozone over the 1985-2003 period and (b) ERA-40 temperature over the 1979-2001 period. The coefficients are expressed as the percentage change in ozone and the change in $\mathrm{K}$, respectively, for a -1-unit change in the Niño-3.4 index. Shaded areas are statistically significant at the $2 \sigma$ level.

a warm or cold ENSO event plays an important role in modifying the wave driving that leads to a change in the BDC. Specifically, cold ENSO events have extratropical tropospheric teleconnections that weaken the wintertime Aleutian low (positive SLP anomaly in Fig. 9b) via the Pacific-North America (PNA) pattern. The latter is interpreted as a Rossby wave train originating from regions of convective forcing in the tropics (e.g., Wallace and Gutzler 1981; Lau et al. 1994). The weakened Aleutian low decreases the wave- 1 eddies with a net decrease in wave driving, a stronger polar vortex, and a decelerated BDC. If the La Niña-like SLP response to solar forcing (Fig. 9a) has a similar effect on wave driving on a decadal time scale, the net result would be a deceleration of the BDC near and approaching solar maxima. To test this further, Fig. 11 plots DJF $\overline{v^{\prime} T^{\prime}}$ deviations at $65^{\circ} \mathrm{N}, 20 \mathrm{hPa}$ (the same location considered in Figs. 7

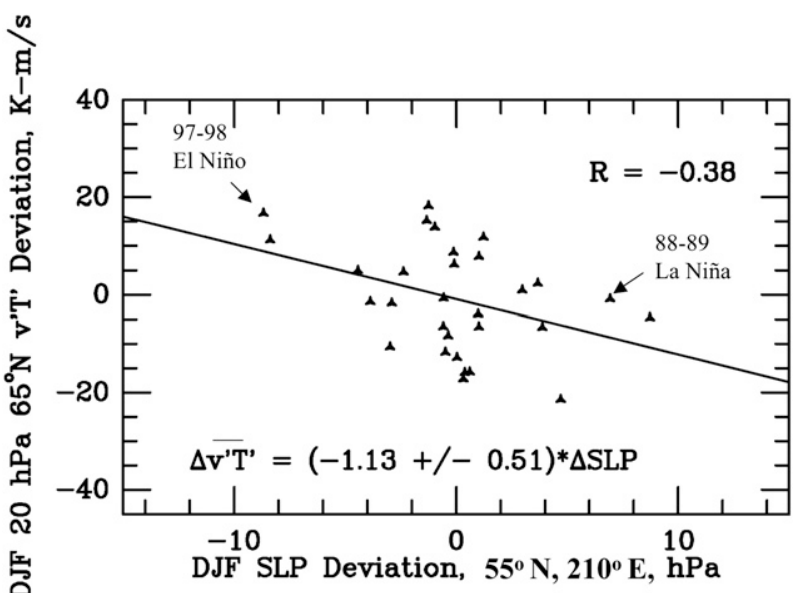

FIG. 11. Linear regression results for DJF zonal mean $20 \mathrm{hPa}$ $v^{\prime} T^{\prime}$ deviations at $65^{\circ} \mathrm{N}$ vs SLP deviations in the Gulf of Alaska region.

and 8) versus DJF SLP deviations at $55^{\circ} \mathrm{N}, 210^{\circ} \mathrm{E}$ (the location of maximum solar response in Fig. 9a) over the 1979-2009 period. Data points corresponding to the largest El Niño and La Niña events during this period are also indicated. The resulting regression relationship indicates that a positive SLP deviation at this location results, on average, in a decrease in wave forcing, which would decelerate the BDC and increase ozone and temperature in the tropical lower stratosphere.

Finally, it is of interest to estimate the approximate solar cycle change in $\overline{v^{\prime} T^{\prime}}$ at $65^{\circ} \mathrm{N}, 20 \mathrm{hPa}$ that would occur based on the solar regression coefficients in the North Pacific shown in Fig. 9a and the regression relationship shown in Fig. 11 . For $\Delta \mathrm{SLP} \simeq 3 \mathrm{hPa}$, corresponding approximately to the observationally estimated change from solar minimum to maximum at $55^{\circ} \mathrm{N}, 210^{\circ} \mathrm{E}$, the change in $20 \mathrm{hPa} \overline{v^{\prime} T^{\prime}}$ in DJF from solar minimum to maximum would be about $3.3 \mathrm{~K} \mathrm{~m} \mathrm{~s}^{-1}$ at $65^{\circ} \mathrm{N}$. The change in $\overline{v^{\prime} T^{\prime}}$ during other seasons cannot be directly estimated without identifying a similar SLP response with known consequences for planetary wave forcing. For simplicity, we assume here that the change in $\overline{v^{\prime} T^{\prime}}$ during the other three seasons is comparable to that known to occur during DJF. Plotted in Fig. 12 (dashed line) is the expected change in $\overline{v^{\prime} T^{\prime}}$ based on the observed monthly $\mathrm{Mg}$ II index, the SLP solar regression coefficients in the Gulf of Alaska region during boreal winter, and the relationship of SLP at $55^{\circ} \mathrm{N}, 210^{\circ} \mathrm{E}$ to $20 \mathrm{hPa} \overline{v^{\prime} T^{\prime}}$ during boreal winter, estimated using the data in Fig. 11. As discussed above, there is some evidence that the SLP response may slightly lead the solar cycle by about $1 \mathrm{yr}$. Therefore, the expected change in $\overline{v^{\prime} T^{\prime}}$ is calculated assuming that the SLP response maximum occurs one year prior to the center of the solar maximum period. Also 


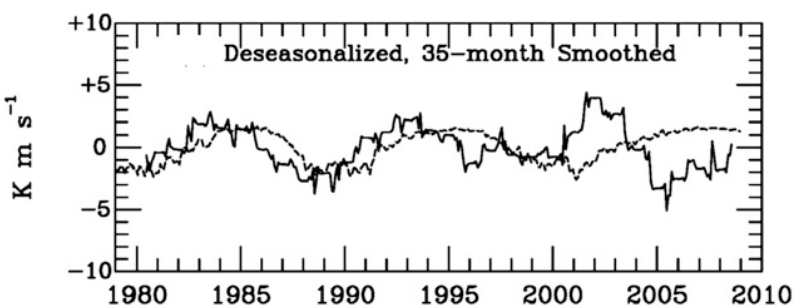

FIG. 12. The solid line is zonal mean meridional eddy heat flux at $65^{\circ} \mathrm{N}, 20 \mathrm{hPa}$ as calculated from NCEP-NCAR reanalysis data, after deseasonalizing and smoothing using a 35-month boxcar filter (as shown in Fig. 7c). The dashed line is the expected change in zonal mean $v^{\prime} T^{\prime}$ at this location based on long-term SLP solar regression coefficients in the North Pacific shown in Fig. 9a and the regression relationship shown in Fig. 11 (see the text).

shown for comparison in Fig. 12 (solid line) is the 35-month smoothed $\overline{v^{\prime} T^{\prime}}$ time series calculated from reanalysis data (also shown in Fig. 7c and in Fig. 8). During the first part of the record ( 1979-95), the expected decadal variation of wave forcing roughly follows the observed $\overline{v^{\prime} T^{\prime}}$ time series. However, after about 2000, the expected decadal variation does not agree well with the smoothed observations. Apparently, if the solar-induced SLP response was involved in producing a modulation of the BDC during solar cycles 21 and 22 , this ceased to be the case during cycle 23 after about 1995-2000.

\section{Time variability of the SLP and lower-stratospheric solar responses}

The first-order analytic study of section 3 found that a decadal variation of extratropical wave forcing is observed that could have contributed substantially to forcing the observed tropical lower-stratospheric solar cycle response, at least during solar cycles 21 and 22. After about 1995-2000, however, the decadal variation of wave forcing became more irregular and this was no longer clearly the case. Also, as mentioned in section 4 , although a statistically significant SLP response to the solar cycle during NH winter is obtained when long time records are analyzed using a suitable statistical model (Fig. 9a), this is only a mean response averaged over many solar cycles. Therefore, for several reasons, it is of interest to investigate the dependence of the SLP and lower-stratospheric response on the time period that is analyzed.

First, it is of interest to test further whether the observed SLP response is a real consequence of solar forcing or whether it could be an artifact of aliasing from natural internal variability. For example, there is a 10 15-yr modulation cycle of ENSO intensity (Sun and $\mathrm{Yu}$ 2009) that could possibly project onto the solar cycle during a limited time period (S. Misios 2011, personal communication). It is also possible that specific ENSO events may alias the results although little evidence for this was found for lower-stratospheric data during the 1979-2003 period (Hood et al. 2010). By analyzing separate time periods, especially periods when 11-yr solar forcing was especially strong versus periods when it was relatively weak, it may be possible to test further the solar origin of the SLP response.

Second, it is necessary to evaluate further whether the lower-stratospheric response is actually coupled to the observed troposphere-ocean response or whether the two responses are separate and correlate only because they are both driven by solar forcing. Although the observed SLP response has characteristics that strongly suggest it plays a role in forcing the observed tropical lower-stratospheric response (i.e., it is La Niña-like and AO-like), it would be preferable to have more definite empirical evidence of a connection between the two. By analyzing separate time intervals when the SLP response was strong and weak, this may become possible.

One simple test to evaluate the reality of the $\mathrm{NH}$ winter solar SLP signal is to compare the response obtained for two separate and long time intervals. For example, one may divide the period from 1880 to 2009 (130 yr) into two approximately equal parts and compare the resulting solar regression coefficients. We have carried out such a test using the Hadley Centre data for the 1880-1945 and the 1946-2009 periods (66 and $64 \mathrm{yr}$, respectively). It was found that the Pacific SLP response pattern was only approximately repeatable during these two time periods. The maximum positive response in the Gulf of Alaska region was found to have an amplitude of about 3-3.5 hPa in both cases but they were not exactly collocated and the amplitude was only statistically significant during the second (1946-2009) period. For comparison, the CMD analysis of van Loon et al. (2007) found a very similar and statistically significant North Pacific SLP response for two separate groups of peak solar years (see their Fig. 1). Thus, the MLR results do not completely confirm the CMD evidence that the responses are almost repeatable.

However, this "reproducibility test" tacitly assumes that 11-yr solar forcing was constant over the 1880-2009 period so that each half of the record is equally likely to show the same SLP solar response. In fact, as measured by sunspot number, 11-yr solar variability was about a factor of 2 larger during the period from about 1935 to 1995 (mean change 130) than it was during the 18801935 period (mean change $\sim 60-70$ ) [see, e.g., Fig. 2e of Gray et al. (2010)]. It is also noteworthy that the solar maximum around year 2001 was about $25 \%$ weaker than the previous two maxima and the next solar maximum is expected to be still weaker because it has been preceded by a long deep minimum. Consequently, the solar forcing 
(a) Gulf of Alaska Location

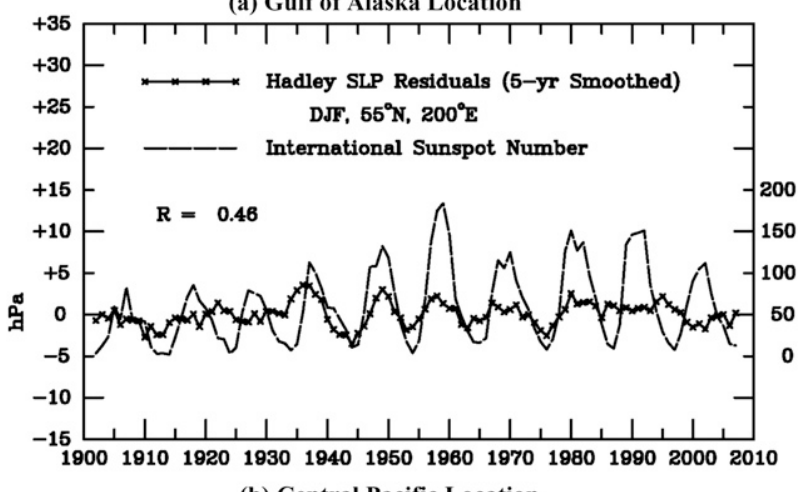

(b) Central Pacific Location

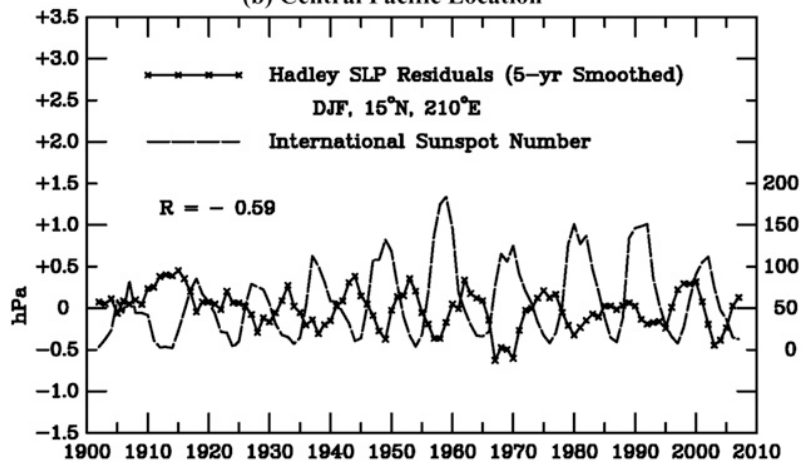

FIG. 13. Sea level pressure residuals (after removing nonsolar sources of interannual variability using the statistical model and after smoothing using a 5-yr running average) at two Pacific locations where the solar regression coefficients are significant. Correlation coefficients $R$ between the smoothed residuals and sunspot number are also given. Note the difference in sea level pressure vertical scales.

function was not constant during the time interval considered here and it is necessary to examine the observed SLP response in more detail as a function of time.

As a first step, Fig. 13 plots the smoothed "solar" SLP residuals (statistical model including all nonsolar terms minus measurements) at two locations where the solar response in Fig. 9a is significant versus time over the 1900-2010 period. These residuals include the solar component of variability plus unmodeled interannual variability. Also plotted for comparison is international sunspot number. Even after minimizing trend, volcanic, ENSO, and PDO contributions to the time series, the correlation coefficient between the 5-yr smoothed residuals and sunspot number is only 0.46 at the location of the positive response in the Gulf of Alaska region (Fig. 13a) and is only -0.59 in the central Pacific region (Fig. 13b). Nevertheless, it is of interest that the correlation between the residuals at both locations is better after about 1935 than before this time and appears to be especially strong between roughly 1940 and 1990 when $11-y r$ solar variations were also strong. It is also of interest that the North Pacific positive SLP response at (a) DJF Sea Level Pressure Change, hPa, Solar Max - Min, 1880-1937

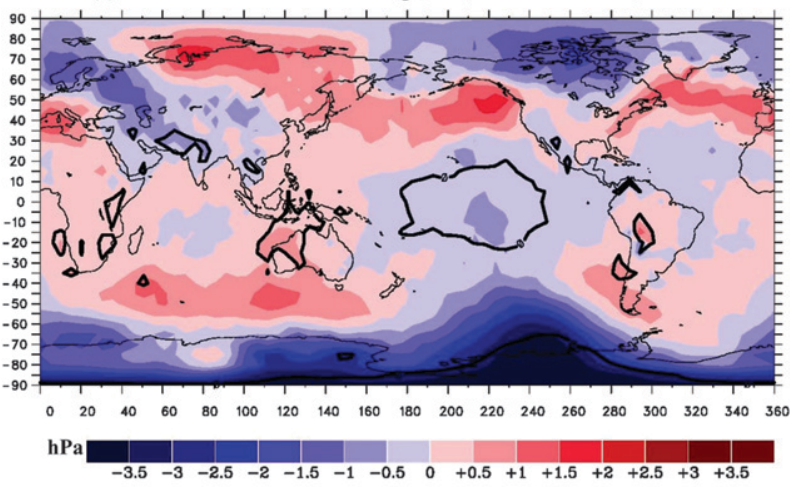

(b) DJF Sea Level Pressure Change, hPa, Solar Max - Min, 1938-1993

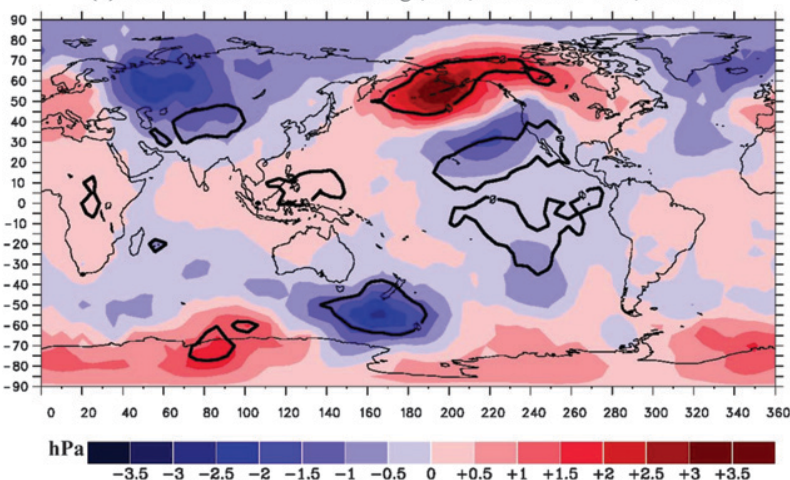

FIG. 14. (a) Sea level pressure solar regression coefficient for $\mathrm{NH}$ winter, calculated from Hadley Centre data over the 1880-1937 period when solar activity was relatively low; format is as in Fig. 9a. (b) As in (a), but for the 1938-93 period when 11-yr solar variability was relatively high.

$55^{\circ} \mathrm{N}, 200^{\circ} \mathrm{E}$ was no longer in phase with the solar cycle after about 1995 .

Although Fig. 13 considers only two grid points, the time variability of the correlation at these two locations confirms that the response shown in Fig. 9a is only the mean response and that it is not present during every solar cycle. However, the tendency for higher correlations after about 1935 when 11 -yr solar variability increased suggests that the SLP response could be a real consequence of solar forcing. To test this hypothesis further, Fig. 14 shows the result of separate MLR analyses of the DJF SLP data over the 1880-1937 period when 11-yr solar variability was weaker and over the 1938-93 period when solar cycle variability was about a factor of 2 larger. Although the solar coefficient for the earlier period (Fig. 14a) still has some characteristics of the time-mean response of Fig. 9a (positive North Pacific response, positive NAO index, weak negative central Pacific response), it is clearly weaker. In particular, the North Pacific response is not statistically significant and a positive response is present over the Siberian Arctic that is inconsistent with an AO pattern. 
(a) DJF Sea Level Pressure Change, hPa, Solar Max - Min, 1979-1993

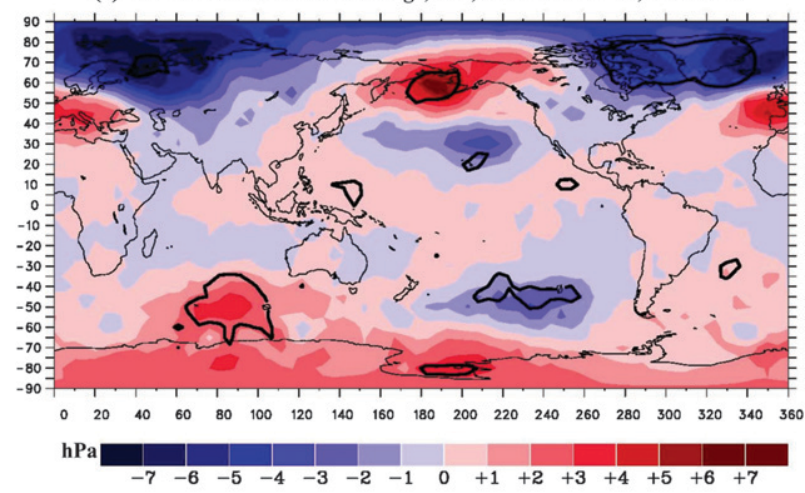

(b) DJF Sea Level Pressure Change, hPa, Solar Max - Min, 1994-2009

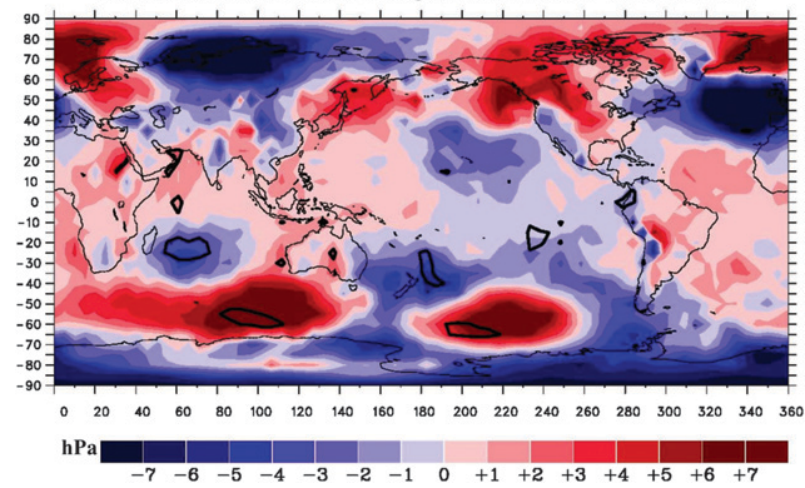

FIG. 15. (a) Sea level pressure solar regression coefficient for NH winter, calculated from Hadley Centre data over the 1979-1993 period. (b) As in (a), but for the 1994-2009 period.

Moreover, the response amplitudes in Fig. 14a are calculated assuming a change in sunspot number of 130 from solar minimum to maximum. The actual mean change in sunspot number from minimum to maximum during the 1880-1937 period was in the range of 60-70. Therefore the amplitudes plotted in Fig. 14a should be reduced by a factor of about 2 to more accurately represent the SLP response during this period. In contrast, the solar coefficient for the later period (Fig. 14b) has a stronger AO-like response in the $\mathrm{NH}$ with a negative Arctic response at all longitudes and a statistically significant positive North Pacific response. Therefore, the results of Fig. 14 are consistent with a significantly stronger NH winter SLP response, on average, during the 1938-93 period of stronger 11-yr solar variability. Superposed on this response during both periods are interannual SLP variations due to other internal and external forcings that are comparable in amplitude to the solar forcing.

Given that there is evidence for a significant SLP response to 11-yr solar variability and that this response varies with time, it is next of interest to evaluate whether the observed lower-stratospheric response also varies with time and whether this time variation correlates with the SLP response amplitude. If so, then this would be consistent with the hypothesis that the two responses are coupled. Global satellite measurements of stratospheric ozone and temperature are only available after late 1978 so the period over which this hypothesis can be tested in this study is limited to the 1979-2009 interval. As mentioned above, the wave forcing data of section 3 suggest that solar modulation of the BDC and forcing of the lower-stratospheric column ozone response was more effective prior to about 1995 than afterward. Figure 13a further suggests that the SLP response in the North Pacific was relatively weak during the last $10-15$ yr of the record. We therefore divide the 1979-2009 interval into two approximately equal parts (1979-93 and 19942009) and compare the SLP and lower-stratospheric responses during these two subintervals. Although short (15 and $16 \mathrm{yr}$, respectively), these subintervals should be sufficiently long to obtain an estimate of the relative strength of the solar cycle SLP response during each period.

The resulting NH winter SLP solar regression coefficients determined from an MLR analysis of the Hadley Centre data for the two separate time periods using the full statistical model are shown in Fig. 15. Although most areas on these plots are not statistically significant (as expected from the short time periods that are analyzed), the response for the earlier period (1979-93; Fig. 15a) is much more consistent with the time-averaged response pattern of Fig. 9a than is the response for the later period (Fig. 15b). Specifically, the North Pacific response is significant, the high-latitude response is negative at all longitudes, and the NAO index is positive. In contrast, in Fig. $15 \mathrm{~b}$, the North Pacific response is not significant, the Arctic response is both positive and negative, and the NAO index is negative. Also, the solar cycle sunspot variation during cycle 23 was less by about $25 \%$ than the variations during cycles 21 and 22. The amplitudes shown in Fig. 15b should therefore be reduced by a corresponding factor.

It is next of interest to compare the lower-stratospheric solar responses of ozone and temperature during the 1979-93 period when the SLP response was stronger (Fig. 15a) with those during the 1994-2009 period when it was weaker (Fig. 15b). Figures 16 and 17 compare the annual mean column ozone and $50-\mathrm{hPa}$ temperature responses during each period while the $\mathrm{NH}$ winter responses are compared in Figs. 18 and 19. In the case of annual mean column ozone (Fig. 16), the response is statistically significant over a wider latitudinal range (extending up to $65^{\circ} \mathrm{S}$ and up to $50^{\circ} \mathrm{N}$ ) during the earlier period. There is also a clear tendency toward higher response amplitudes in the subtropics and middle latitudes than in the tropics $\left(20^{\circ} \mathrm{S}-20^{\circ} \mathrm{N}\right)$. The increase in response amplitude from the tropics to the subtropics can also be seen in Fig. 16b but it is not as pronounced. In 
(a) Annual Mean Column Ozone \% Change, Solar Max - Min, 1979-1993

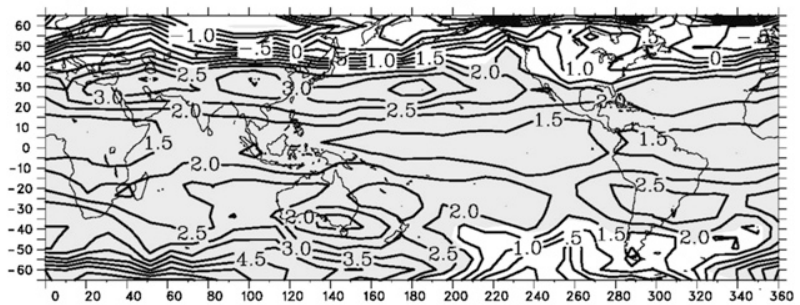

(b) Annual Mean Column Ozone \% Change, Solar Max - Min, 1994-2009

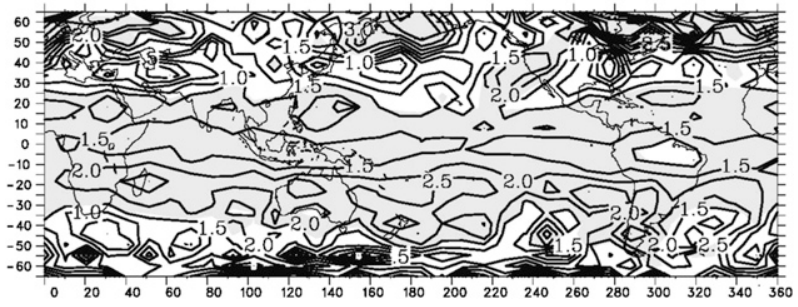

FIG. 16. Annual mean solar cycle column ozone regression coefficients (change from solar minimum to maximum) calculated from version 8 TOMS/SBUV data for (a) 1979-93 and (b) 19942009.

the case of annual mean 50-hPa temperature (Fig. 17), the solar response amplitude is markedly reduced and is not statistically significant at all latitudes during the later period as compared to the earlier period. In the case of DJF column ozone (Fig. 18), the solar response is again statistically significant to higher latitudes, especially in the $\mathrm{NH}$, during the earlier period when the SLP response was strong. There is again a tendency toward much lower response amplitudes $(<1 \%)$ at tropical latitudes and higher amplitudes in the subtropics (up to $5 \%$ in the northern subtropics) during the earlier period. There is a similar change in amplitude from the tropics to the subtropics during the later period (Fig. 18b) but it is less pronounced and is limited in statistical significance only to the SH. Finally, Fig. 19 shows that the 50-hPa solar temperature response during DJF is again high in amplitude $(1.2-2.0 \mathrm{~K})$ and statistically significant only during the earlier period. Moreover, the temperature response is also higher in the subtropics than in the tropics during the earlier period (Fig. 19a). Comparing Fig. 18a to Fig. 19a, a correlation is evident between the regional column ozone and temperature responses in the subtropics during this season and time period.

As argued in sections 2 and 3, there is good evidence that the tropical lower-stratospheric responses of ozone and temperature to 11-yr solar forcing involve a solar modulation of the BDC. However, the latitude dependence of the NH winter column ozone and 50-hPa temperature responses during the 1979-93 period (as well as the existence of apparent regional responses) strongly suggests a role for the Hadley circulation, in addition to (a) Annual Mean 50 hPa Temp. Change, Kelvin, Solar Max - Min, 1979-1993

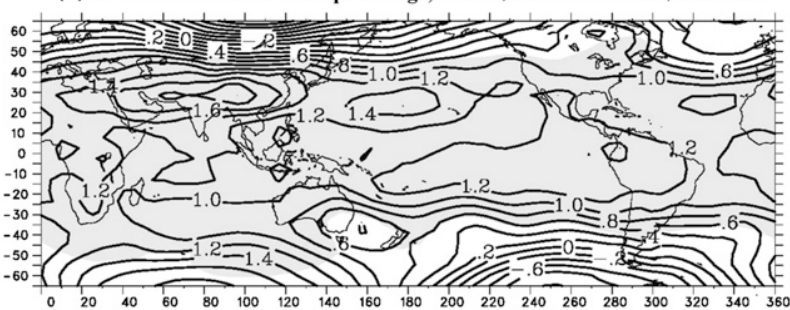

(b) Annual Mean 50 hPa Temp. Change, Kelvin, Solar Max - Min, 1994-2009

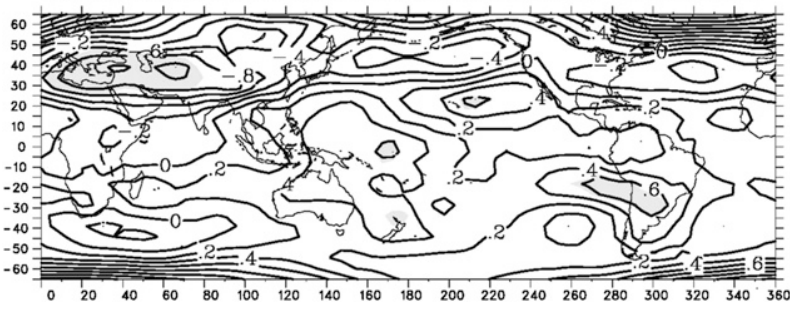

FIG. 17. Annual mean solar cycle 50-hPa temperature regression coefficients (change from solar minimum to maximum) calculated from NCEP-NCAR reanalysis data for (a) 1979-93 and (b) 19942009.

the BDC, in producing the lower-stratospheric response. Although the Hadley circulation is mainly tropospheric, it can influence vertical velocities in the lowermost stratosphere where part of the ozone column resides. In particular, the DJF column ozone response is especially weak and statistically insignificant in the eastern tropical $\mathrm{Pa}$ cific during the 1979-93 period (Fig. 18a) while there is a large positive response of more than $5 \%$ in the subtropical North Pacific during the same period.

This response pattern strongly suggests an accelerated Hadley circulation associated with nonlinear oceanatmosphere coupling, similar to that which drives the El Niño-Southern Oscillation, but operating on the solar cycle time scale. This would be consistent with the bottom-up mechanism for amplifying an initial small solar total irradiance forcing, leading to a La Niña-like SST and SLP solar response (Meehl et al. 2009; van Loon et al. 2007, and references therein). However, it can also be consistent with top-down initial forcing via the stratosphere to perturb the Hadley circulation (Haigh et al. 2005; Matthes et al. 2006, and references therein), thereby starting the same air-sea amplification process. In either case, strong coupling between the surface climate and lower-stratospheric responses is implied. Current models indicate that both TSI and solar UV forcing via the stratosphere are necessary to simulate the Pacific climate response to the solar cycle (Meehl et al. 2009; $\mathrm{Bal}$ et al. 2011). Since the lower-stratospheric response is probably involved in forcing the troposphere-ocean response, the coupling inferred here would represent a positive feedback for solar forcing of climate by amplifying the 
(a) DJF Column Ozone, \% Change, Solar Max - Min, 1979-1993

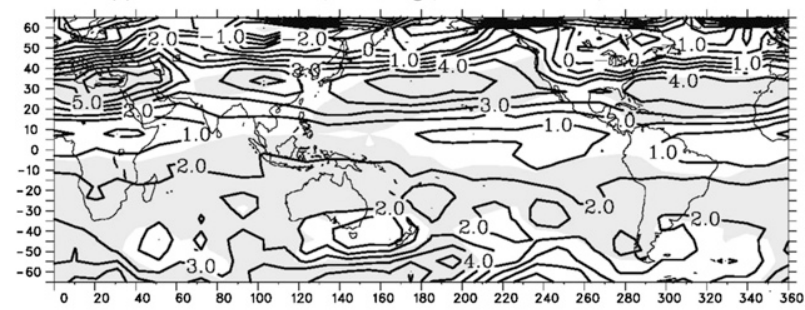

(b) DJF Column Ozone, \% Change, Solar Max - Min, 1994-2009

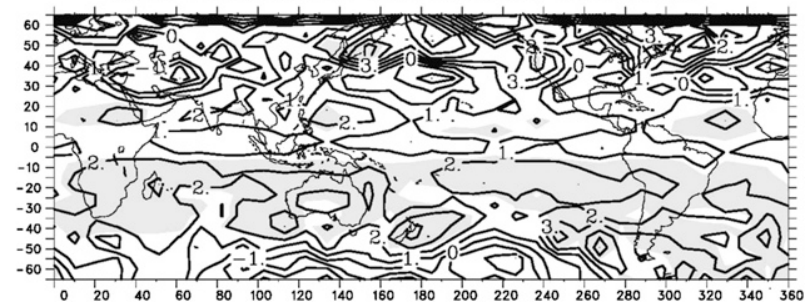

FIG. 18. NH winter (DJF) solar cycle column ozone regression coefficients (change from solar minimum to maximum) calculated from version 8 TOMS/SBUV data for (a) 1979-93 and (b) 19942009.

lower-stratospheric response, which then further enhances the surface climate response.

\section{Summary and conclusions}

The MLR analyses of annual and zonal mean ozone and temperature data in section 2 (Fig. 2) confirm previous results indicating the existence, on average, during the 1979-2003 period of a solar cycle response in the tropical and subtropical lower stratosphere, in addition to that which occurs in the upper stratosphere. Comparisons with a chemistry-climate model simulation (Fig. 6; WACCM3 coupled to CCSM3 with a prescribed QBO) indicate that the response minimum in the tropical middle stratosphere is most probably a consequence of either a solar-modulated QBO or aliasing from QBO events during the limited time record. However, the observed amplitude and latitudinal extent of the lowerstratospheric ozone and temperature responses are too large to be explained by this mechanism alone. Also, MLR analyses of column ozone and 50-hPa temperature data over the same time period demonstrate an asymmetry of the response toward the summer hemisphere, suggesting an origin involving a reduction of the BrewerDobson circulation near and approaching solar maxima.

Analyses of monthly mean meridional eddy heat flux (proportional to the vertical component of the EliassenPalm planetary wave flux) yield evidence for a decadal variation of extratropical wave forcing (Fig. 7) that could be involved in producing the solar-modulated $\mathrm{BDC}$ and the tropical lower-stratospheric response, a (a) DJF 50 hPa Temp. Change, Kelvin, Solar Max - Min, 1979-1993

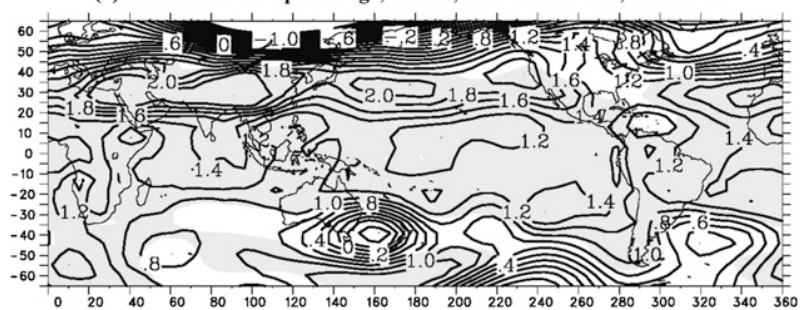

(b) DJF 50 hPa Temp. Change, Kelvin, Solar Max - Min, 1994-2009

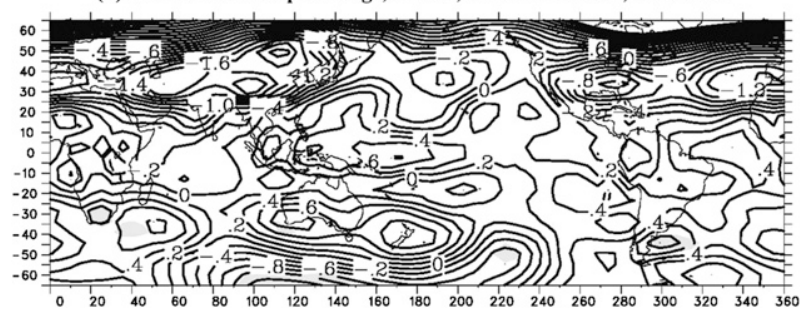

FIG. 19. NH winter (DJF) solar cycle $50-\mathrm{hPa}$ temperature regression coefficients (change from solar minimum to maximum) calculated from NCEP-NCAR reanalysis data for (a) 1979-93 and (b) 1994-2009.

possibility that is supported by analytic model calculations (Fig. 8). However, the decadal variation of wave forcing becomes much more irregular after about 1995 and the contribution of decadal BDC variability to producing the solar cycle column ozone variation is much less clear after this time.

MLR analyses of NH winter sea level pressure over the 1880-2009 period confirm previous results indicating the existence, on average, of statistically significant responses to 11-yr solar forcing in the Pacific sector (Fig. 9a). In particular, a positive response with mean amplitude about $3 \mathrm{hPa}$ (for a change in sunspot number of 130 from solar minimum to maximum) occurs in the Gulf of Alaska region, implying a weakening and westward shift of the Aleutian low near solar maxima. There is also a region of weak negative response in the central Pacific. The SLP response in NH winter resembles an AO pattern and has a positive NAO index, although the latter is not statistically significant. It also has characteristics similar to the SLP response to a moderate La Niña event (Fig. 9b), although the zonal structures are not the same. Since La Niña events are known to produce a weakening, on average, of the BDC and an increase in tropical and subtropical lower-stratospheric ozone and temperature (Fig. 10), it is likely that the solar cycle SLP response will also enhance lower-stratospheric ozone and temperature in the tropics and subtropics near solar maxima. In particular, the weakening of the Aleutian low reduces the planetary wave driving at northern midlatitudes, which reduces the extratropical meridional eddy heat flux (Fig. 11). However, the expected decadal 
variation of eddy heat flux based on the time averaged SLP response in NH winter only follows the observed variation up until about 1995-2000 (Fig. 12).

Time variability of the SLP and lower-stratospheric responses is investigated in section 5 for the purpose of testing further the reality of the SLP response and whether periods of strong SLP response are associated with periods of strong lower-stratospheric response, as expected if the two are dynamically coupled. Evidence is obtained that the SLP response is approximately repeatable in separate long time periods and was strongest during the $\sim 1938-93$ period when 11-yr solar variations were largest (Figs. 13 and 14). However, the SLP response is not clearly present during every solar cycle because of internal climate variability and other external forcings. After about 1995, the positive DJF SLP response in the Gulf of Alaska region is no longer in phase with the solar cycle (Fig. 13a). MLR analyses of SLP at all grid points for NH winter confirm that the solar cycle response pattern is clearly present during the 1979-93 period but is only weakly present during the 1994-2009 period. MLR analyses of column ozone and 50-hPa temperature (Figs. 16-19) show that the lowerstratospheric response is stronger and extends to higher latitudes during the earlier (1979-93) period than during the later (1994-2009) period. In particular, the 50-hPa temperature response is no longer statistically significant during the later period. It is therefore concluded that the available data (covering only the 1979-2009 period) are consistent with a stronger lower-stratospheric response during periods when the DJF SLP response is most clearly present.

Finally, the column ozone solar response during $\mathrm{NH}$ winter (Figs. 4a and 18) has significantly lower amplitudes at tropical latitudes $\left(<20^{\circ}\right)$ than at subtropical and middle latitudes. This was especially true in the eastern Pacific sector during the 1979-93 period when the SLP response was relatively strong. A similar tendency is seen in the $50-\mathrm{hPa}$ temperature solar response with regional response anomalies in the northern subtropics correlating approximately with regional column ozone response anomalies (Fig. 19a). The increased ozone and temperature response amplitudes in the subtropics are consistent with an acceleration and/or poleward extension of the Hadley circulation under solar maximum conditions, which produces increased subsidence, advectively increasing the ozone column and temperature at those latitudes. Thus, the lower-stratospheric response appears to also be driven, in part, by changes in the Hadley circulation (or its upward extension into the lowermost stratosphere) from solar minimum to maximum. A positive acceleration of the Hadley circulation, especially in the eastern Pacific region, is consistent with a La Niña-like troposphere-ocean response, implying a role for atmosphere-ocean coupling in amplifying the surface climate response to solar forcing (e.g., van Loon et al. 2007). This therefore represents further, more direct evidence that the troposphere-ocean response and the lower-stratospheric response are dynamically coupled. If solar ultraviolet forcing via the stratosphere is strongly involved in initiating the troposphere-ocean response, as current models suggest (e.g., Meehl et al. 2009; Bal et al. 2011), then it follows that the lower-stratospheric response could represent an additional positive feedback for amplifying the solar-induced surface climate response.

Further work is clearly needed to establish more definitively the existence and nature of the coupled lowerstratospheric and SLP responses investigated here. Although reanalysis data are somewhat less reliable prior to the era of continuous global satellite measurements, it may be possible to extend the lower-stratospheric temperature record back to the 1950s, which would then allow further tests of the provisional conclusion that the lower-stratospheric response is stronger during periods of strong SLP response. The conclusion that the troposphere-ocean response, as measured using SLP data, is strongest during the period of high 11-yr solar variability ( 1938-93) may also be tested further by investigating whether a La Niña-like SST response is also present during that period. Finally, more detailed comparisons of the observed $11-\mathrm{yr}$ response in both the troposphere and lower stratosphere with simulations by CCMs with and without a coupled ocean and with and without a simulated or prescribed QBO (e.g., WACCM4) would also assist in determining the origin of the observed lower-stratospheric response and whether a coupled SLP response is necessary to produce it.

Acknowledgments. The stratospheric MLR analyses were supported in part under Grant NNX10AQ63G from the NASA Living With a Star Targeted Research and Technology program and in part through a subcontract from the Naval Research Laboratory under Grant NNH08AI67 (J. McCormack, P.I.) issued through the LWS TR\&T program. Comparisons with WACCM model simulations are supported under a grant from the Climate Dynamics branch of the National Science Foundation. MLR analyses of the WACCM3/CCSM3 model output used in the construction of Fig. 6 were done by Christian Blume and Katja Matthes of the Deutsches GeoForschungsZentrum, Potsdam, Germany, and the Free University of Berlin. These model simulations were designed by Katja Matthes and Francisco Sassi. Early CMD analyses of the same model simulations were also generously provided by Julie Arblaster in 2010. Dan 
Marsh suggested the method for accounting for autocorrelation adopted in section 2. Updated SAGE II ozone profile monthly zonal means were provided by W. J. Randel and F. Wu of NCAR and were based on data originally obtained from the NASA Langley Research Center Radiation and Aerosols branch. Hadley Centre SLP and SST data were obtained from the U.K. Met Office Hadley Centre Observations internet site (hadobs.metoffice.com). The NCEP-NCAR Reanalysis monthly temperature and daily temperature and height fields (used for the calculation of $v^{\prime} T^{\prime}$ ) were obtained from the NOAA Climate Prediction Center internet site (www.cpc.ncep.noaa.gov). Stefan Brönnimann kindly provided reconstructed QBO and N3.4 time series covering the 1880-2009 period, as was needed for the SLP and SST analyses. Updated values of the daily Mg II solar ultraviolet index were provided by Rodney Viereck of NOAA. One of us (LLH) thanks I. Cnossen for helpful discussions and we thank two anonymous reviewers for critical comments on an earlier version of the paper that led to significant improvements in the analysis.

\section{REFERENCES}

Andrews, D. G., J. R. Holton, and C. B. Leovy, 1987: Middle Atmosphere Dynamics. Academic Press, 489 pp.

Austin, J., L. L. Hood, and B. E. Soukharev, 2007: Solar cycle variations of stratospheric ozone and temperature in simulations of a coupled chemistry-climate model. Atmos. Chem. Phys., 7, 1693-1706.

—, and Coauthors, 2008: Coupled chemistry climate model simulations of the solar cycle in ozone and temperature. J. Geophys. Res., 113, D11306, doi:10.1029/2007JD009391.

Bal, S., S. Schimanke, T. Spangehl, and U. Cubasch, 2011: On the robustness of the solar cycle signal in the Pacific region. Geophys. Res. Lett., 38, L14809, doi:10.1029/2011GL047964.

Balachandran, N. K., D. Rind, P. Lonergan, and D. T. Shindell, 1999: Effects of solar cycle variability on the lower stratosphere and the troposphere. J. Geophys. Res., 104, 27 321-27 339.

Brasseur, G., and S. Solomon, 2005: Aeronomy of the Middle Atmosphere. Springer, $644 \mathrm{pp}$.

Brönnimann, S., J. L. Annis, C. Vogler, and P. D. Jones, 2007: Reconstructing the quasi-biennial oscillation back to the early 1900s. Geophys. Res. Lett., 34, L22805, doi:10.1029/2007GL031354.

Calvo, N., R. Garcia, W. Randel, and D. Marsh, 2010: Dynamical mechanism for the increase in tropical upwelling in the lowermost tropical stratosphere during warm ENSO events. J. Atmos. Sci., 67, 2331-2340.

Christoforou, P., and S. Hameed, 1997: Solar cycle and the Pacific “centers of action." Geophys. Res. Lett., 24, 293-296.

Cnossen, I., and H. Lu, 2011: The vertical connection of the quasibiennial oscillation-modulated 11 year solar cycle signature in geopotential height and planetary waves during Northern Hemisphere early winter. J. Geophys. Res., 116, D13101, doi:10.1029/2010JD015427.

,,- C. J. Bell, L. J. Gray, and M. M. Joshi, 2011: Solar signal propagation: The role of gravity waves and stratospheric sudden warmings. J. Geophys. Res., 116, D02118, doi:10.1029/ 2010JD014535.
Cordero, E. C., and T. R. Nathan, 2005: A new pathway for communicating the 11-year solar cycle signal to the QBO. Geophys. Res. Lett., 32, L18805, doi:10.1029/2005GL023696.

Crooks, S., and L. Gray, 2005: Characterization of the 11-year solar signal using a multiple regression analysis of the ERA-40 dataset. J. Climate, 18, 996-1015.

Fischer, P., and K. K. Tung, 2008: A reexamination of the QBO period modulation by the solar cycle. J. Geophys. Res., 113, D07114, doi:10.1029/2007JD008983.

Frame, T. H. A., and L. J. Gray, 2010: The 11-yr solar cycle in ERA-40 data: An update to 2008. J. Climate, 23, 2213-2222.

Free, M., and D. J. Seidel, 2009: Observed El Niño-Southern Oscillation temperature signal in the stratosphere. J. Geophys. Res., 114, D23108, doi:10.1029/2009JD012420.

Frith, S. M., and R. S. Stolarski, 2005: Merged profile ozone data from the SBUV/SBUV2 series of instruments. Eos, Trans. Amer. Geophys. Union, 86 (Fall Meeting Suppl.), Abstract A23B-0943.

Garcia, R. R., D. R. Marsh, D. E. Kinnison, B. A. Boville, and F. Sassi, 2007: Simulation of secular trends in the middle atmosphere. J. Geophys. Res., 112, D09301, doi:10.1029/ 2006JD007485.

García-Herrera, R., N. Calvo, R. R. Garcia, and M. A. Giorgetta, 2006: Propagation of ENSO temperature signals into the middle atmosphere: A comparison of two general circulation models and ERA-40 reanalysis data. J. Geophys. Res., 111, D06101, doi:10.1029/2005JD006061.

Garfinkel, C. I., and D. L. Hartmann, 2008: Different ENSO teleconnections and their effects on the stratospheric polar vortex. J. Geophys. Res., 113, D18114, doi:10.1029/2008JD009920.

Garny, H., G. E. Bodeker, and M. Dameris, 2007: Trends and variability in stratospheric mixing: 1979-2005. Atmos. Chem. Phys., 7, 5611-5624.

Gray, L. J., E. Drysdale, B. Lawrence, and T. Dunkerton, 2001a: Model studies of the interannual variability of the Northern Hemisphere stratospheric winter circulation: The role of the quasi-biennial oscillation. Quart. J. Roy. Meteor. Soc., 127, 1413-1432.

—, S. Phipps, T. Dunkerton, M. Baldwin, E. Drysdale, and M. Allen, 2001b: A data study of the influence of the equatorial upper stratosphere on Northern Hemisphere stratospheric sudden warmings. Quart. J. Roy. Meteor. Soc., 127, 1985-2003.

— , S. Rumbold, and K. Shine, 2009: Stratospheric temperature and radiative forcing response to 11-year solar cycle changes in irradiance and ozone. J. Atmos. Sci., 66, 2402-2417.

_ , and Coauthors, 2010: Solar influences on climate. Rev. Geophys., 48, RG4001, doi:10.1029/2009RG000282.

Haigh, J. D., 1996: The impact of solar variability on climate. Science, 272, 981-984.

, 1999: A GCM study of climate change in response to the 11-year solar cycle. Quart. J. Roy. Meteor. Soc., 125, 871-892, doi:10.1002/qj.49712555506.

_ 2003: The effects of solar variability on the Earth's climate. Philos. Trans. Roy. Soc. London, 361, 95-111.

- M. Blackburn, and R. Day, 2005: The response of tropospheric circulation to perturbations in lower-stratospheric temperature. J. Climate, 18, 3672-3685.

Hamilton, K., 2002: On the quasi-decadal modulation of the stratospheric QBO period. J. Climate, 15, 2562-2565.

Holton, J. R., P. H. Haynes, M. E. McIntyre, A. R. Douglass, R. B. Rood, and L. Pfister, 1995: Stratosphere-troposphere exchange. Rev. Geophys., 33, 403-439. 
Hood, L. L., 1997: The solar cycle variation of total ozone: Dynamical forcing in the lower stratosphere. J. Geophys. Res., 102, 1355-1370.

— 2004: Effects of solar UV variability on the stratosphere. Solar Variability and its Effect on Climate, Geophys. Monogr., Vol. 141, Amer. Geophys. Union, 283-304.

—, and J. P. McCormack, 1992: Components of interannual ozone change based on Nimbus 7 TOMS data. Geophys. Res. Lett., 19, 2309-2312.

— tropical lower stratosphere: The role of extratropical wave forcing. J. Atmos. Sci., 60, 2389-2403.

— B. E. Soukharev, and J. P. McCormack, 2010: Decadal variability of the tropical stratosphere: Secondary influence of the El Niño-Southern Oscillation. J. Geophys. Res., 115, D11113, doi:10.1029/2009JD012291.

Kalnay, E., and Coauthors, 1996: The NCEP/NCAR 40-year Reanalysis Project. Bull. Amer. Meteor. Soc., 77, 437-471.

Kinnersley, J. S., and S. Pawson, 1996: The descent rates of the shear zones of the equatorial QBO. J. Atmos. Sci., 53, 19371949.

Kodera, K., and Y. Kuroda, 2002: Dynamical response to the solar cycle. J. Geophys. Res., 107, 4749, doi:10.1029/ 2002JD002224.

Labitzke, K., 2004: On the signal of the 11-year sunspot cycle in the stratosphere and its modulation by the quasi-biennial oscillation. J. Atmos. Sol.-Terr. Phys., 66, 1151-1157.

, 2007: Solar variation and stratospheric response. Space Sci. Rev., 125, 247-260.

_ solar cycle, the QBO and the atmosphere. Part I: The troposphere and stratosphere in the Northern Hemisphere in winter. J. Atmos. Terr. Phys., 50, 197-206.

Lau, K., P. Sheu, and I. Kang, 1994: Multiscale low-frequency circulation modes in the global atmosphere. J. Atmos. Sci., 51, 1169-1193.

Lean, J., J. Beer, and R. Bradley, 1995: Reconstruction of solar irradiance since 1610: Implications for climate change. Geophys. Res. Lett., 22, 3195-3198.

Lee, H., and A. K. Smith, 2003: Simulation of the combined effects of solar cycle, quasi-biennial oscillation, and volcanic forcing on stratospheric ozone changes in recent decades. J. Geophys. Res., 108, 4049, doi:10.1029/2001JD001503.

Mantua, N. J., S. R. Hare, Y. Zhang, J. M. Wallace, and R. C. Francis, 1997: A Pacific interdecadal climate oscillation with impacts on salmon production. Bull. Amer. Meteor. Soc., 78, 1069-1079.

Marsh, D. R., 2010: Response of the whole atmosphere to solar cycle changes in radiative and geomagnetic forcing. Proc. 12th Symp. on Solar-Terrestrial Physics, Berlin, Germany, SCOSTEP, 178 .

_- and R. Garcia, 2007: Attribution of decadal variability in lower-stratospheric tropical ozone. Geophys. Res. Lett., 34, L21807, doi:10.1029/2007GL030935.

Matthes, K., U. Langematz, L. Gray, K. Kodera, and K. Labitzke, 2004: Improved 11-year solar signal in the Freie Universität Berlin Climate Middle Atmosphere Model (FUBCMAM). J. Geophys. Res., 109, D06101, doi:10.1029/ 2003JD004012.

, Y. Kuroda, K. Kodera, and U. Langematz, 2006: Transfer of the solar signal from the stratosphere to the troposphere: Northern winter. J. Geophys. Res., 111, D06108, doi:10.1029/ 2005JD006283.
- - and Coauthors, 2007: Report on the first SOLARIS workshop 4-6 October 2006, Boulder, Colorado, USA. SPARC Newsletter, No. 28, Toronto, ON, Canada, 19-22. [Available online at http://www.sparc-climate.org/publications/ newsletter/.]

- D. R. Marsh, R. Garcia, D. Kinnison, F. Sassi, and S. Walters, 2010: Role of the QBO in modulating the influence of the 11 year solar cycle on the atmosphere using constant forcings. J. Geophys. Res., 115, D18110, doi:10.1029/2009JD013020.

McCormack, J. P., 2003: The influence of the 11-year solar cycle on the quasi-biennial oscillation. Geophys. Res. Lett., 30, 2162 , doi:10.1029/2003GL018314.

- D. E. Siskind, and L. L. Hood, 2007: Solar-QBO interaction and its impact on stratospheric ozone in a zonally averaged photochemical transport model of the middle atmosphere. J. Geophys. Res., 112, D16109, doi:10.1029/2006JD008369.

Meehl, G. A., and J. M. Arblaster, 2009: A lagged warm eventlike response to peaks in solar forcing in the Pacific region. J. Climate, 22, 3647-3660.

— W. Washington, T. M. L. Wigley, J. Arblaster, and A. Dai, 2003: Solar and greenhouse gas forcing and climate response in the twentieth century. J. Climate, 16, 426-444.

_ J. M. Arblaster, G. Branstator, and H. van Loon, 2008: A coupled air-sea response mechanism to solar forcing in the Pacific region. J. Climate, 21, 2883-2897.

_,- _ K. Matthes, F. Sassi, and H. van Loon, 2009: Amplifying the Pacific climate system response to a small 11-year solar cycle forcing. Science, 325, 1114-1118.

Nathan, T. R., and E. C. Cordero, 2007: An ozone-modified refractive index for vertically propagating planetary waves. J. Geophys. Res., 112, D02105, doi:10.1029/2006JD007357.

Pascoe, C. L., L. J. Gray, S. A. Crooks, M. N. Juckes, and M. P. Baldwin, 2005: The quasi-biennial oscillation: Analysis using ERA-40 data. J. Geophys. Res., 110, D08105, doi:10.1029/ 2004JD004941.

Plumb, R. A., and J. Eluszkiewicz, 1999: The Brewer-Dobson circulation: Dynamics of the tropical upwelling. J. Atmos. Sci., 56, 868-890.

Powell, A. M., Jr., and J. Xu, 2011: Possible solar forcing of interannual and decadal stratospheric planetary wave variability in the Northern Hemisphere: An observational study. J. Atmos. Sol.-Terr. Phys., 73, 825-838.

Randel, W. J., 1993: Global variations of zonal mean ozone during stratospheric warming events. J. Atmos. Sci., 50, 3308-3321.

— , and $\mathrm{F} . \mathrm{Wu}, 1996$ : Isolation of the ozone QBO in SAGE II data by singular-value decomposition. J. Atmos. Sci., 53, 25462559.

— 1979-2005; Variability, trends, and comparisons with column ozone data. J. Geophys. Res., 112, D06313, doi:10.1029/ 2006JD007339.

_, R. Garcia, and F. Wu, 2002a: Time-dependent upwelling in the tropical lower stratosphere estimated from the zonal-mean momentum budget. J. Atmos. Sci., 59, 2141-2152.

_ - F. Wu, and R. Stolarski, 2002b: Changes in column ozone correlated with the stratospheric EP flux. J. Meteor. Soc. Japan, 80, 849-862.

_ temperature trends. J. Geophys. Res., 114, D02107, doi:10.1029/ 2008JD010421.

_ , R. R. Garcia, N. Calvo, and D. Marsh, 2009b: ENSO influence on zonal mean temperature and ozone in the 
tropical lower stratosphere. Geophys. Res. Lett., 36, L15822, doi:10.1029/2009GL039343.

Rayner, N. A., P. Brohan, D. E. Parker, C. K. Folland, J. J. Kennedy, M. Vanicek, T. J. Ansell, and S. F. B. Tett, 2006: Improved analyses of changes and uncertainties in sea surface temperature measured in situ since the mid-nineteenth century: The HadSST2 dataset. J. Climate, 19, 446-469.

Reinsel, G. C., A. J. Miller, E. C. Weatherhead, L. E. Flynn, R. M. Nagatani, G. C. Tiao, and D. J. Wuebbles, 2005: Trend analysis of total ozone data for turnaround and dynamical contributions. J. Geophys. Res., 110, D16306, doi:10.1029/ 2004JD004662.

Remsberg, E. E., 2008: On the response of Halogen Occultation Experiment (HALOE) stratospheric ozone and temperature to the 11-year solar cycle forcing. J. Geophys. Res., 113, D22304, doi:10.1029/2008JD010189.

Rind, D., J. Lean, J. Lerner, P. Lonergan, and A. Leboissitier, 2008: Exploring the stratospheric/tropospheric response to solar forcing. J. Geophys. Res., 113, D24103, doi:10.1029/2008JD 010114.

Robock, A., 2000: Volcanic eruptions and climate. Rev. Geophys., 38, 191-219.

Roy, I., and J. Haigh, 2010: Solar cycle signals in sea level pressure and sea surface temperature. Atmos. Chem. Phys., 10, $3147-$ 3153.

Salby, M. L., and P. F. Callaghan, 2000: Connection between the solar cycle and the QBO: The missing link. J. Climate, 13, 2652-2662.

— , and — 2006: Evidence of the solar cycle in the tropical troposphere. J. Geophys. Res., 111, D21113, doi:10.1029/ 2006JD007133.

Semeniuk, K., and T. G. Shepherd, 2001: Mechanisms for tropical upwelling in the stratosphere. J. Atmos. Sci., 58, 30973115.

Shibata, K., and M. Deushi, 2008: Long-term variations and trends in the simulation of the middle atmosphere 1980-2004 by the chemistry-climate model of the Meteorological Research Institute. Ann. Geophys., 26, 1299-1326.

Shindell, D. T., D. Rind, N. K. Balachandran, J. Lean, and P. Lonergan, 1999: Solar cycle variability, ozone, and climate. Science, 284, 305-308.

_ , G. Faluvegi, R. L. Miller, G. A. Schmidt, J. E. Hansen, and S. Sun, 2006: Solar and anthropogenic forcing of tropical hydrology. Geophys. Res. Lett., 33, L24706, doi:10.1029/ 2006GL027468.

Simpson, I., M. Blackburn, and J. D. Haigh, 2009: The role of eddies in driving the tropospheric response to stratospheric heating perturbations. J. Atmos. Sci., 66, 1347-1365.

Smith, A. K., and K. Matthes, 2008: Decadal-scale periodicities in the stratosphere associated with the solar cycle and the QBO. J. Geophys. Res., 113, D05311, doi:10.1029/2007JD009051.

Smith, T. M., and R. W. Reynolds, 2003: Extended reconstruction of global sea surface temperatures based on COADS data (1854-1997). J. Climate, 16, 1495-1510.

- , and — 2004: Improved extended reconstruction of SST (1854-1997). J. Climate, 17, 2466-2477.

$\longrightarrow, \ldots$, T. C. Peterson, and J. Lawrimore, 2008: Improvements to NOAA's historical merged land-ocean surface temperature analysis (1880-2006). J. Climate, 21, 2283-2296.

Solomon, S., R. W. Portmann, R. R. Garcia, L. W. Thomason, L. R. Poole, and M. P. McCormick, 1996: The role of aerosol variations in anthropogenic ozone depletion at northern midlatitudes. J. Geophys. Res., 101, 6713-6727.
Soukharev, B. E., and L. Hood, 2001: Possible solar modulation of the equatorial quasi-biennial oscillation: Additional statistical evidence. J. Geophys. Res., 106, 14 855-14 868.

- , and - 2006: Solar cycle variation of stratospheric ozone: Multiple regression analysis of long-term satellite data sets and comparisons with models. J. Geophys. Res., 111, D20314, doi:10.1029/2006JD007107.

Steinbrecht, W., B. Hassler, H. Claude, P. Winkler, and R. S. Stolarski, 2003: Global distribution of total ozone and lower stratospheric temperature variations. Atmos. Chem. Phys., 3, 1421-1438.

Stenchikov, G., A. Robock, V. Ramaswamy, M. D. Schwarzkopf, K. Hamilton, and S. Ramachandran, 2002: Arctic Oscillation response to the 1991 Mount Pinatubo eruption: Effects of volcanic aerosols and ozone depletion. J. Geophys. Res., 107, 4803, doi:10.1029/2002JD002090.

Sun, F., and J.-Y. Yu, 2009: A 10-15-yr modulation cycle of ENSO intensity. J. Climate, 22, 1718-1735.

Thomason, L. W., L. R. Poole, and T. Deshler, 1997: A global climatology of stratospheric aerosol surface area density deduced from Stratospheric Aerosol and Gas Experiment II measurements: 1984-1994. J. Geophys. Res., 102 (D7), 89678976.

Thompson, D. W., J. J. Kennedy, J. M. Wallace, and P. D. Jones, 2008: A large discontinuity in the mid-twentieth century in observed global-mean surface temperature. Nature, 453, 646649, doi:10.1038/nature06982.

Tiao, G., and Coauthors, 1990: Effects of autocorrelation and temporal sampling schemes on estimates of trend and spatial correlation. J. Geophys. Res., 95, 20 507-20 517.

Tourpali, K., C. S. Zerefos, D. S. Balis, and A. F. Bais, 2007: The 11-year solar cycle in stratospheric ozone: Comparison between Umkehr and SBUVv8 and effects on surface erythemal irradiance. J. Geophys. Res., 112, D12306, doi:10.1029/ 2006JD007760.

Tung, K. K., and C. D. Camp, 2008: Solar cycle warming at the Earth's surface in NCEP and ERA-40 data: A linear discriminant analysis. J. Geophys. Res., 113, D05114, doi:10.1029/ 2007JD009164.

— and J. Zhou, 2010: The Pacific's response to surface heating in 130 yr of SST: La Niña-like or El Niño-like? J. Atmos. Sci., 67, 2649-2657.

van Loon, H., and G. A. Meehl, 2008: The response in the Pacific to the sun's decadal peaks and contrasts to cold events in the Southern Oscillation. J. Atmos. Sol.-Terr. Phys., 70, 1046-1055.

$\longrightarrow,-$, and D. Shea, 2007: Coupled air-sea response to solar forcing in the Pacific region during northern winter. J. Geophys. Res., 112, D02108, doi:10.1029/2006JD007378.

Viereck, R., and L. Puga, 1999: The NOAA Mg II core-to-wing solar index: Construction of a 20-year time series of chromospheric variability from multiple satellites. J. Geophys. Res., 104, 9995-10 005.

von Storch, H., and F. W. Zwiers, 2002: Statistical Analysis in Climate Research. Cambridge University Press, $494 \mathrm{pp}$.

Wallace, J. M., and D. S. Gutzler, 1981: Teleconnections in the geopotential height field during the Northern Hemisphere winter. Mon. Wea. Rev., 109, 784-812.

Wang, H. J., D. M. Cunnold, and X. Bao, 1996: A critical analysis of Stratospheric Aerosol and Gas Experiment ozone trends. J. Geophys. Res., 101, 12 495-12 514.

Wang, Y.-M., J. Lean, and N. R. Sheeley Jr., 2005: Modeling the sun's magnetic field and irradiance since 1713. Astrophys. J., 625, 522-538. 
White, W. B., J. Lean, D. R. Cayan, and M. D. Dettinger, 1997: Response of global upper ocean temperature to changing solar irradiance. J. Geophys. Res., 102, 3255-3266.

WMO, 2007: Scientific assessment of ozone depletion: 2006. WMO Global Ozone Research and Monitoring Project Rep. 50. [Available online at http://www.wmo.int/pages/prog/arep/ gaw/ozone_2006/ozone_asst_report.html.]

Zerefos, C. W., K. Tourpali, B. R. Bojkov, D. S. Balis, B. Rognerund, and I. S. A. Isaksen, 1997: Solar activity-total column ozone relationships: Observations and model studies with heterogeneous chemistry. J. Geophys. Res., 102, 15611569.

Zhang, Y., J. M. Wallace, and D. S. Battisti, 1997: ENSO-like interdecadal variability: 1900-93. J. Climate, 10, 10041020.

Zhou, J., and K.-K. Tung, 2010: Solar cycles in 150 years of global sea surface temperature data. J. Climate, 23, 32343248 . 